\title{
Design and Development of Degradable Polyethylenimines for Delivery of DNA and Small Interfering RNA: An Updated Review
}

\author{
Chong-Su Cho \\ Department of Agricultural Biotechnology and Research Institute for Agriculture and Life Sciences, Seoul National University, \\ Seoul 151-921, Republic of Korea \\ Correspondence should be addressed to Chong-Su Cho, chocs@snu.ac.kr
}

Received 24 September 2012; Accepted 12 October 2012

Academic Editors: K. Hokamoto and A. O. Neto

Copyright (๑) 2012 Chong-Su Cho. This is an open access article distributed under the Creative Commons Attribution License, which permits unrestricted use, distribution, and reproduction in any medium, provided the original work is properly cited.

Polyethylenimine (PEI), considered as the most potent and promising alternative carrier to viral vectors, has been studied as the "state of the art" among various polymers for nonviral gene delivery applications for many years. Although PEI-based carrier minimizes the bottlenecks associated with viral vectors such as unwanted immunogenicity and production problems, the toxic side effects of PEI prevent its rapid advancements due to nondegradable nature. In this regard, various degradable cross-linking and/or grafting agents have been linked to synthesize degradable PEIs in order to minimize the toxicity and improve the efficacy of PEI-mediated gene carriers. This paper describes an update on various cross-linkers and grafting agents in the design and development of degradable PEI derivatives and their potential applications for effective delivery of DNA in vitro and in vivo. The molecular weight (MW) of PEI and the structural relationship to its cellular toxicity and transfection ability were also discussed. Finally, the potential applications of various degradable PEIs for small interfering RNA (siRNA)-mediated gene silencing were also covered.

\section{Introduction}

As a promising treatment strategy, gene therapy is a powerful approach to cure a wide range of both inherited and acquired diseases, including varieties of cancers, cystic fibrosis, severe combined immunodeficiency (SCID), in addition to Parkinson, Alzheimer, and infectious disease such as AIDS. The application of gene therapy is oriented to either attenuation or overriding of the malfunctioning gene by transferring a desired genetic material to targeted cells for achieving therapeutic effect [1]. Although gene therapy is a promising strategy, the success of this approach is limited clinically by the lack of safe and efficient delivery systems [2]. In spite of progressing recent clinical advancements [3] using viral vectors, the unwanted immunogenicity, limited DNA cargo capacity, and problem with large-scale production associated with viral delivery system have led a continuous interest in developing synthetic nonviral gene carriers [4]. As a potential synthetic gene delivery agent, a diverse collection of materials has been investigated, including lipids, polysaccharides, polypeptides, dendrimers, and inorganic nanoparticles
[5]. However, a suboptimal gene delivery efficacy of these materials in vivo compared to viral vectors has prevented their wide-spread clinical use [6]. Although viruses have been naturally selected to effectively navigate the multiple intraand extracellular barriers for successful gene transfer, the diversity and flexibility of polymer chemistries open promising potentials to discover and implement functionalities that offer not only efficient gene transfer but also improved and superior biocompatibility, enhanced formulation stability and low cellular toxicity $[7,8]$.

Among the variety of nonviral vectors, cationic polymers are holding enormous potentials with many essential advantages for effective delivery of gene or small interference RNA (siRNA). As a transfection vector, cationic polymers are widely investigated due to their unique characteristics with which they can form polyelectrolyte complexes with gene and be able to protect them from DNase enzymes [9]. They can be specifically formulated for the purpose of application with desired physiological and physicochemical properties, such as cell-specific targeting or degradation under certain 
environment. A wide range of cationic polymers have been designed and characterized to achieve effective gene transfection, including poly (L-lysine) (PLL), polyethylenimine (PEI), gelatin, polybrene, poly (vinyl imidazole), polyamidoamine dendrimers, diethylaminoethyl dextran, poly [Lhistidine-g-poly (L-lysine)], poly ( $\beta$-amino ester), and chitosan. Various recent reports have elaborately described their gene-binding and complexation capabilities as well as in vitro and in vivo capabilities [10-14].

Among various cationic polymers, PEI is one of the most potent nonviral polymeric gene vectors due to its $\mathrm{pH}$ buffering capacity. This unique property of PEI helps the gene carriers to escape the endosomal barrier avoiding lysosomal degradation which is an essential step to achieve high gene transfection [9]. Therefore, it has been widely implemented for delivery of DNA or siRNA to the targeted cells for effective treatment [15]. However, the problems associated with PEI are its lack of degradability and hence is too toxic for therapeutic applications [9], although PEImediated toxicity depends on its molecular weight (MW) and type of PEI structure. The low molecular weight (LMW) linear or branched PEI has low cytotoxicity compared to their high MW counterparts. Moreover, the linear PEIs are more tolerable than the branched ones. However, LMW PEIs suffer from poor transfection efficiency [16]. To overcome these limitations, a number of researchers have explored their investigation on designing and developing degradable PEIs by cross-linking them with various degradable crosslinkers for intracellular degradation through simple hydrolysis, low endosomal $\mathrm{pH}$-depended hydrolysis, degradation by enzymatic function, and cytosolic reductive action by glutathione [9]. As therefore, these PEIs exhibited high transfection efficiency with low cytotoxicity by the rapid in situ degradation of the polymer into LMW water-soluble fragments, which can be easily processed and excreted by the cells.

This paper covers recent advances of designing degradable PEIs as potent and safe carrier systems for DNA and siRNA delivery. It also explains PEI structure relationship to its transfection activity and cytotoxicity. The transfection efficiency of DNA and silencing capability of siRNA based on degradable PEIs as carrier systems prepared with a variety of cross-linkers are also discussed.

\section{Advantages of Degradable PEIs}

The transfection efficiency and the cytotoxicity of PEI are closely linked to its structural activity. This structural relationship is an essential issue to be investigated in detail in order to show the effect of chemical structure, hydrophobicity, charge density, and molecular weight of PEI on its transfection activity as well as cytotoxicity. This information could be helpful to explain a basis for further optimization of the synthesized polymers. In nonviral polymeric gene delivery, some polymers show effective gene expression capability, whereas some others are inefficient to show transfection activity although they provide stable polyplexes formation after gene-binding and condensation. The reason behind this might be the difference between the endosomal release mechanism such as the buffering capacity of PEI or the intrinsic membrane active properties. Different polymers have their own endosomal release mechanism, which affects their transfection activity. Therefore, the membrane dispersion activity of polymers should be investigated to gather knowledge on their ultimate fate in the endosome and also it is important to get information about the possible toxic side-effects [17].

In order to obtain an enhanced transfection activity, the cationic polymer should be able to self-assemble with DNA through electrostatic interaction and condensed it into positively charged polymer/DNA complexes. Also the complexes should be able to protect DNA from degradation by DNase in the cytosol for successful transfection. For safe and effective gene delivery, polymer degradation is another prerequisite milestone to be met. Degradation of polymers could reduce cytotoxicity due to easy elimination of degraded small MW byproducts through excretion pathway. Degradation is also important for unpackaging the polymeric complexes and release of DNA or siRNA for enhanced transfection or silencing. Nondegradable PEI, on the other hand, accumulates in vivo due to lack of degradation and thus, unable to be excreted, resulting in potential cytotoxicity and thus, hampers to show efficient transfection activity [18]. Therefore, it can be revealed that PEI structural function has an intimate relationship to its transfection efficiency and cellular cytotoxicity. The beauty of polymer chemistry offers a great advantage to modulate the structural activity of PEI as desirable ways where the synthesis of degradable PEI derivatives prepared by crosslinking with various degradable cross-linkers has enormous potentials to become a safe and effective carrier system for gene or siRNA.

\section{Classification of Degradable PEI Derivatives}

The design for synthesis of PEI derivatives with degradable properties is oriented either with the inclusion of degradable backbones or reducible linkages. Degradable PEIs can be classified into linear, branched, and grafted PEIs, based on the differences in structure and classified according to degradable linkages.

\subsection{Degradable PEIs according to Structural Differences}

3.1.1. Degradable Linear and Branched PEIs. Various degradable linkages such as ester, disulfide, amide, imine, carbamate, and ketal are potentially used to synthesize degradable PEIs through cross-linking between PEIs and the crosslinkers.The first degradable cross-linked PEI was reported by Gosselin et al., who synthesized a cross-linked LMW PEI through dithiobis succinimidylpropionate (DSP) and dimethyl 3, 3' -dithiobispropionimidate (DTBP) as the crosslinking agents for the purpose of highly effective gene delivery [19]. These cross-linkers introduced disulfide bonds in the cross-linked PEI structure to acquire degradable properties and provided effective gene transfection with 
reduced cytotoxicity in Chinese hamster ovary $(\mathrm{CHO})$ cells, because the introduced disulfide bonds by cross-linking were reduced by glutathione, which is an intracellular reducing agent. It is noted that the transfection activity by the polymer-mediated gene delivery varies according to the nature of cross-linking agents, conjugation manner and the charge ratio (N/P) (nitrogen/phosphate) or weight ratio. As a cross-linking agent, disuccinimidyl suberate (DSS) and ethylene glycol bis (succinimidylsuccinate) (EGS) were also used to cross-link LMW PEI to prepare degradable PEIs [20]. The synthesized degradable PEIs having amide-linkages showed transfection activity of 550 folds higher compared to the LMW PEI and also superior by an order of magnitude than the "state-of-the-art" branched PEI $(25 \mathrm{kDa})$ with low toxicity. Furthermore, the in vivo transfection result showed that the degradable cross-linked PEI exhibited 17 to 80-fold higher gene transfection efficiency compared to the unmodified PEI, which was also 2-fold increased than that of PEI $25 \mathrm{kDa}$ without increasing any significant cytotoxicity level [20]. In another report, Forrest et al. used 1,3-butanediol (or 1,6-hexanediol) diacrylate as a crosslinking agent with LMW PEI $(800 \mathrm{Da})$ to synthesize the ester cross-linked degradable PEI derivative [21]. It was revealed that synthesized degradable PEI had a high MW of $14 \mathrm{kDa}$, because both the primary and secondary amine groups were reacted with the acrylate groups resulting in a highly branched and cross-linked final product. The half-life of the cross-linked degradable PEI was $4 \mathrm{~h}$, owing to rapid hydrolysis of the polymeric ester linkages at physiological environments, producing the diol linkers and amino acid as byproducts [21]. The physicochemical properties of the degradable PEI-mediated binding of DNA exhibited similar phenomenon with the widely investigated branched PEI $25 \mathrm{kDa}$; however, they expressed highly impressive gene transfection activity between 2- and 16-fold higher in comparison to the PEI $25 \mathrm{kDa}$ in MDA-MB-231, a breast cancer cell with much lower cellular toxicity [21]. Degradable cross-linked PEIs were also synthesized based on oligoamines and various cross-linkers such as DTBP, DSP, and hexanediol diacrylate by the polymer library technique [22]. These cross-linked degradable PEIs possessed both disulfide bonds as well as ester linkages to improve their biodegradability. The degradable polymers showed higher gene transfection capacity than the high molecular weight liner PEI $(22 \mathrm{kDa})$ with hemocompatibility, because of the reductive cleavage of the disulfide bonds and the ester linkage hydrolysis. It is important to know that the reaction condition during synthesis of degradable PEI is an important parameter to regulate the degradable properties of the polymer. Kloeckner et al. described that the temperature of the Michael addition reaction, an evergreen reaction procedure for polymer synthesis, is important for the regulation of the synthesized polymer degradability [22]. An elevated reaction temperature (such as 60 or $80^{\circ} \mathrm{C}$ ) provided higher amide/ester ratios compared to lower temperature (such as $20^{\circ} \mathrm{C}$ ) and hence showed slow degradation half-lives [23].

Park et al. cross-linked linear PEI (MW: 423 Da) with poly (ethylene glycol) (PEG) diacrylate having three different MWs $(258,575$, and 700$)$ to synthesize degradable PEIs as shown in Figure 1 [24]. Molecular weight (MW) of the synthesized polymer varied from 7,980 to 12,860 according to the reaction conditions. The copolymer (PEI-alt-PEG) rapidly degraded at physiological conditions, where the high MW (575) showed short half-life of $8 \mathrm{~h}$ than that of PEI-altPEG having low MW (258). Interestingly, the transfection efficiency was significantly affected by the variation of MW of PEG in the PEI-alt-PEG copolymer in various investigated cell lines as shown in Figure 2 due to the shielding effect raised from the PEG segments, where the shielding effects of PEG in the copolymer increased with the increase of PEG MW, resulting in a reduced interaction of the PEI-altPEG/DNA complexes to the cells [24].

The degradable linear PEIs possess a low amine density since they contain merely the tertiary amine groups at the sterically crowed environment [25]. Thus, degradable branched PEIs have gained interest over the linear ones as they have a number of merits owing to their high amine density. Since the linear PEIs have limited amine density, they may not be effective for condensation as well as protection of DNA, which ultimately cause inefficiency to show gene transfection. Therefore, branched PEIs are the automatic choice for synthesizing degradable PEIs, although there should be proper optimization to control the reaction conditions, because branched PEIs have primary, secondary, and tertiary amine groups. In terms of degradability, branched degradable PEIs degrade slowly owing to less water accessibility in their branched structure for ester hydrolysis [26]; on the other hand, linear PEIs have short half-lives and show reduction in chain length rapidly even a few cleavages, which facilitate fast decrease in molecular weight [25].

The synthesis of degradable branched PEI by crosslinking of the LMW PEI (1200 Da) with the oligo (L-lacticco-succinic acid) was reported by Petersen et al. [20]. The degradation of the synthesized copolymer was facilitated via base catalyzed hydrolysis of amide bonds. Due to the amide cross-links at the polymeric structure, the degradation of the polymer was very slow with reduced half-life at physiological $\mathrm{pH}$ ( $\mathrm{pH}$ 7.4). This degradable PEI derivative showed significantly increased (10-fold) transfection activity compared to the starting PEI of $8 \mathrm{kDa}$ with lower cytotoxicity [20]. Ahn et al. applied various LMW PEIs (600, 1200, and $1800 \mathrm{Da}$ ) to cross-link with bifunctional PEG in order to synthesize degradable PEI with carbamate linkage. The synthesized degradable PEI cross-linked using PEG showed significantly higher transfection activity (3-times) in human embryonic kidney (293T) cells compared to the starting PEI 1800 with good cell viability percentages $(80 \%)$. However, the gene transfection capability of the copolymer was lower than that of the high molecular weight branched PEI $25 \mathrm{kDa}$ [27]. The degradable branched PEI was also synthesized by acid labile imine-linkers through simple reaction conditions [28]. In this case, the polymer degraded rapidly at acidic environments with a half-life of $2.5 \mathrm{~h}$ and exhibited transfection efficiency similar to PEI $25 \mathrm{kDa}$ without perceptible cellular toxicity.

Degradable PEI containing disulfide linkages has also been considered as a highly efficient gene carrier system. There are various reports that described the synthesis of 


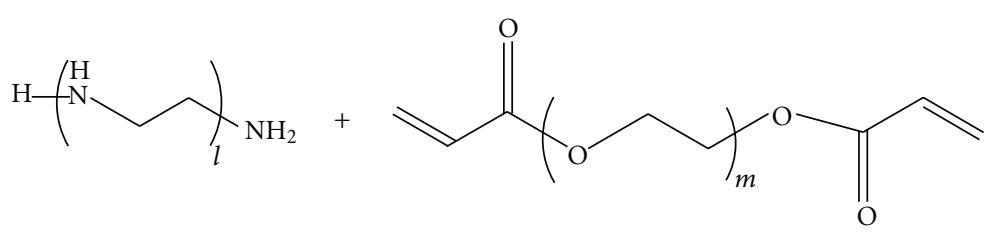

PEI linear (Mn: 423)

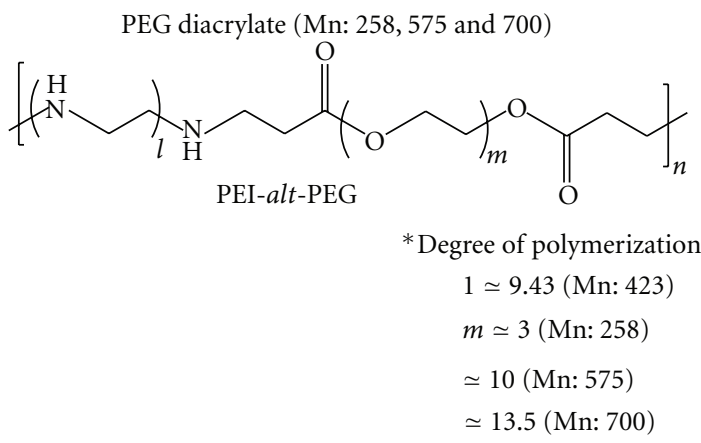

FIGURE 1: Proposed reaction scheme for synthesis of degradable PEI (PEI-alt-PEG) based on PEG diacrylate and linear PEI [24].

disulfide-conjugated degradable PEIs where the disulfide bonds can be cross-linked either in the main chain or the side chain of the synthesized polymer. Gosselin et al. pioneered the synthesis of the disulfide linkage-based degradable PEIs, as described earlier, where the degradable PEI contained disulfide bonds in the main chain [19]. Lin and Engbersen investigated the synthesis of poly (amido amine) and their structural effects on effective gene transfection [29]. They synthesized poly (amido-ethylenimines) (PAEIs) by Michael addition reaction of cystamine bisacrylamide (CBA) with three different ethylenediamine (EDA), diethylenetriamine (DETA), and triethylenetetramine (TETA). These synthesized copolymers containing three disulfide linkages exhibited excellent transfection activity with 20 folds higher compared to PEI $25 \mathrm{kDa}$ in various cell lines, including NIH3T3, endothelial and smooth muscle cells [29]. Recently, Zhang and Vinogradov demonstrated the synthesis of disulfidelinked degradable PEIs in the main chain between the CBA and the LMW linear PEI (423 Da) [30]. The copolymer provided almost 5 -fold higher gene transfection capacity than that of nondegradable PEI $(22 \mathrm{kDa})$ in brain capillary endothelial cells in the presence of serum owing to the mild reduction of the disulfide chain of the carrier. Sun et al. also used the CBA as the cross-linker to LMW PEI $(800 \mathrm{Da})$ to synthesize disulfide-containing degradable PEI [31]. In another report, Peng et al. used LMW PEI $(800 \mathrm{Da})$ to cross-link with methylthiirane as a thiolation and disulfide cross-linking agent in the side chain [32]. Both these disulfides containing degradable PEI derivatives facilitated comparable gene transfer ability with PEI $25 \mathrm{kDa}$ with much lower toxicity due to the polymer degradation as a result of the reductively degradable disulfide linkages in the copolymer [31,32]. Breunig et al. prepared disulfidecontained degradable PEIs in the side chain by cross-linking LMW PEIs with a combination of $N, N^{\prime}$-bis (terbutoxycarbonyl) cysteine, and 4-(4,6-dimethoxy $[1,3,5]$ triazin-2yl) 4-methyl-morpholiniumchlorid hydrate. The polymers showed high gene expression as well as cell survival of about $98.7 \%[33]$.

In recent past, Kim et al. synthesized degradable hyperbranched PEI through a Michael-type addition reaction of LMW PEI $(1800 \mathrm{Da})$ and poloxamer diacrylate $(2500 \mathrm{Da})$ as shown in Figure 3 [34]. An effective DNA condensation and physicochemical properties such as small particle size at nanometer scale $(150 \mathrm{~nm})$ were achieved by the synthesized copolymer. Moreover, the modified degradable PEI exhibited much higher transfection capability compared to the PEI $25 \mathrm{kDa}$ in various cancer cells such as A549, 293T, and HepG2 with significantly increased cell viability, due to the presence of hydrophobic segments in the degradable PEI derivative. It is important to mention that the polymer showed a slight serum-dependency on transfection activity in A549 cells when the polymer contained an increased poloxamer up to 30 wt.-percent [34]. In another work, Arote et al. synthesized degradable branched PEI by Michael addition reaction between the branched PEI varying three different LMWs $(600,1200,1800 \mathrm{Da})$ with polycaprolactone (PCL) diacrylate as shown in Figure 4 [35]. The final MW of the PCL-based degradable PEI (PCL/PEI copolymer) ranged from 2,288 to 15,460 according to the difference in MW of the reacted PEI and feed ratio of PEI to PCL. The half-life of the PCL/PEI copolymer was 4.5 to 5 days, which is longer compared to that of linear PEI-alt-PEG [24], because PCLbased degradable PEI consisted of hydrophobic PCL crosslinked to branched PEI. The synthesized polymer showed stable DNA condensation ability and particle sizes less than $200 \mathrm{~nm}$, which was highly effective for efficient endocytosis into cells. Moreover, the polymers exhibited significantly less cytotoxicity in various cell lines (293T, HeLa, and HepG2). The most important was that the transfection efficiency of PCL/PEI copolymer was 15-20 folds higher compared to that of PEI $25 \mathrm{kDa}$ and comparable to Lipofectamine used as a control, due to the hydrophobic properties of PCL and the reduced toxicity of the polymer. Furthermore, a successful 

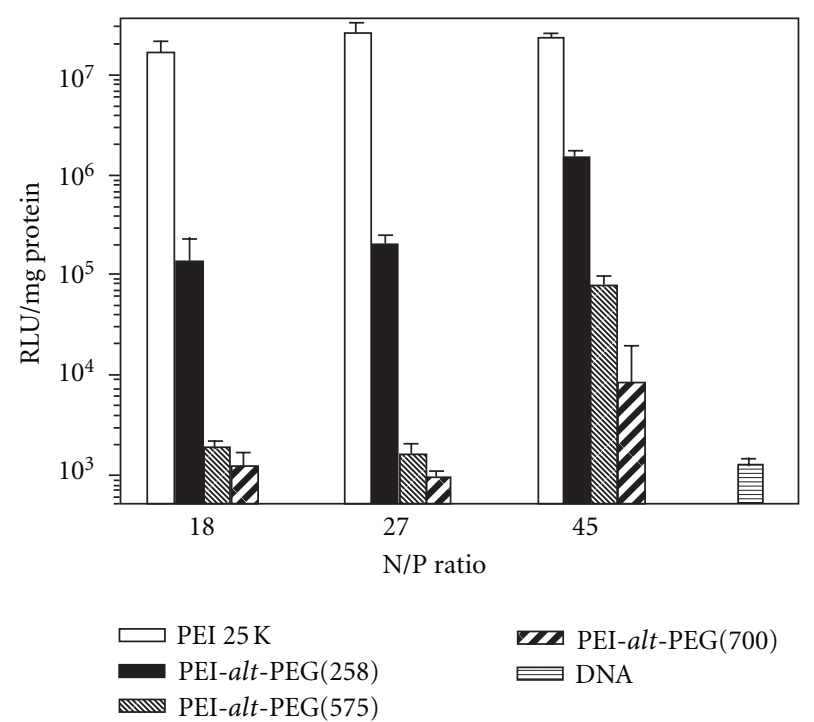

(a)

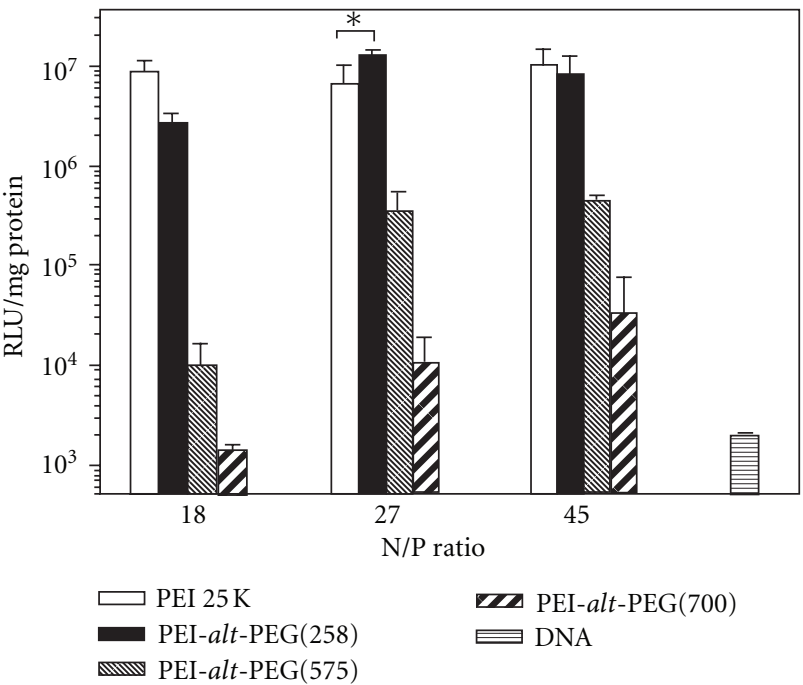

(b)

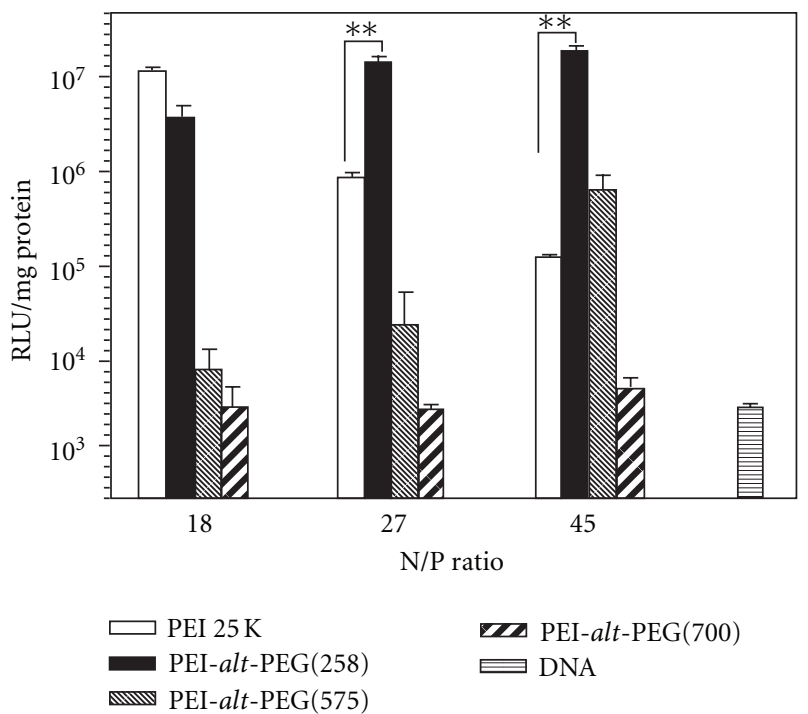

(c)

Figure 2: Transfection efficiency of (PEI-alt-PEG)/DNA (pGL3-control) complexes at various N/P ratios and in various cell lines $\left({ }^{*} P<0.01\right.$, ** $P<0.001$ ) (a) HeLa, (b) HepG2, and (c) MG63 cells ( $n=3$, error bars represent standard deviation) [24].

and enhanced in vivo transfection was observed after aerosol administration of the polymer/DNA complexes in mice [35]. The same group further synthesized and optimized another derivative of degradable PEI based on glycerol dimethacrylate (GDM) as a cross-linking agent to conjugate LMW branched PEI (1,200 Da) as shown in Figure 5 [36]. The degradation of the copolymer occurred slowly with a half-life of 9-10 days owing to the polymeric hyperbranched structure. The synthesized GDM/PEI copolymer stably condensed DNA as well as protected from DNase and elucidated a preferable characteristics of the polymer/DNA complexes with suitable sizes $(\sim 150 \mathrm{~nm})$ and surface charges of the particles $(30-55 \mathrm{mV})$ at physiological $\mathrm{pH}$. Impressively, the GDM/PEI system elucidated a significantly less cellular toxicity with much higher transfection capability than that of PEI $25 \mathrm{kDa}$ as well as the commercial Lipofectamine in three different cell lines (HeLa, HepG2, and 293T), owing to the synergistic effect of hyperosmotic property of GDM segments and proton sponge-active PEI backbone in the copolymer. The degradable GDM/PEI-mediated gene carrier also showed enhanced in vivo gene transfection ability [36]. Recently, Islam et al. also implemented the hyperosmotic active degradable PEI concept, where the polymer was synthesized from sorbitol dimethacrylate (SDM) to crosslink the LMW linear PEI (423 Da) through Michael addition reaction as shown in Figure 6 [37]. The reaction condition was set up at $80^{\circ} \mathrm{C}$ to increase the cross-linking efficiency and the final molecular weight of the polymer. The synthesized degradable polymer showed excellent DNA-binding capacity as well as protection of DNA from DNase enzymes at very 


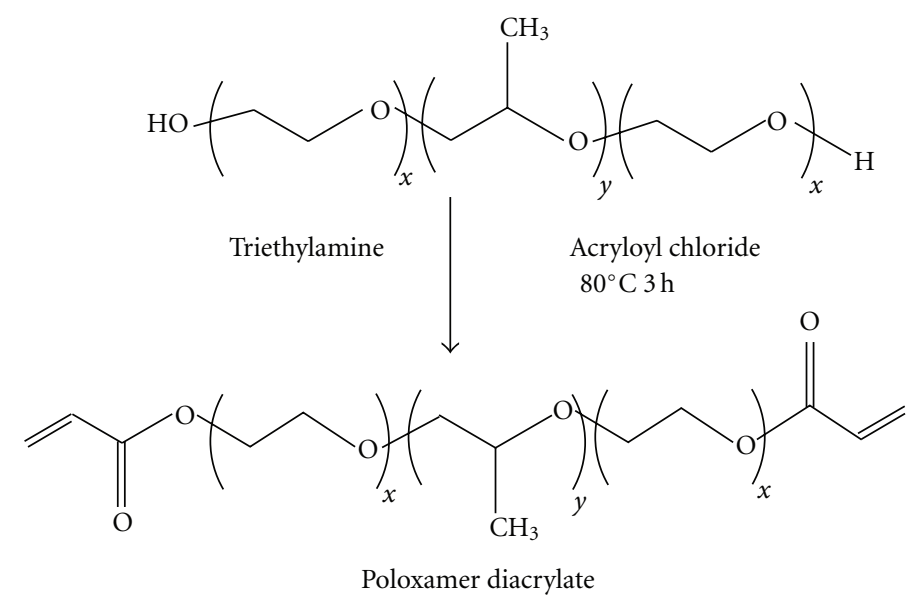

(a)

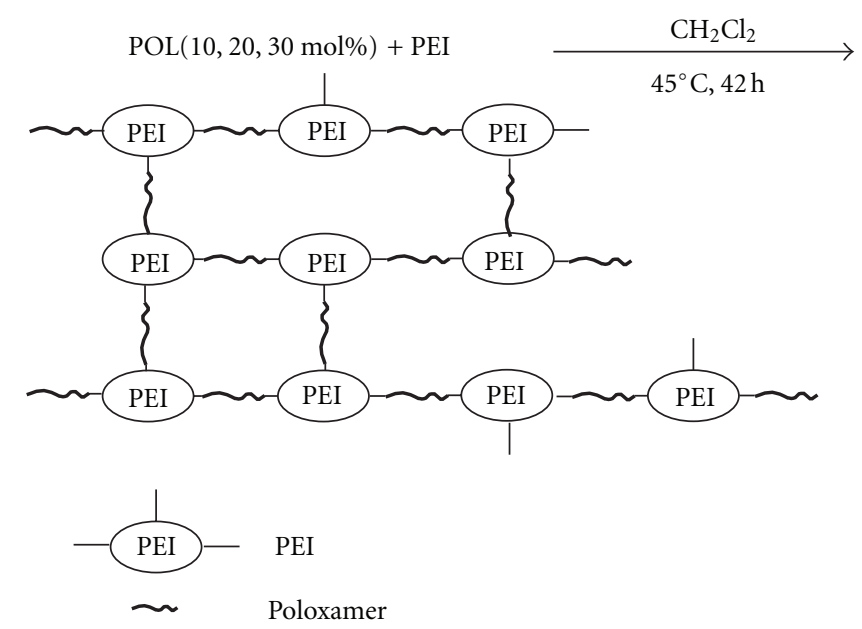

(b)

FIGURE 3: (a) Synthetic scheme of poloxamer diacrylate. (b) Synthetic scheme of PEA based on poloxamer diacrylate and PEI by Michael addition reaction [34].

low N/P ratio (such as N/P of 0.5 ); it even contained LMW linear PEI (423 Da) which was reported ineffective to condense DNA even at N/P ratio of 50 [24]. The nanosized ( $200 \mathrm{~nm}$ ) polymer/DNA complexes exhibited excellent stability in the presence of various serum percentages since they significantly retained the structural activity of the complexes in serum conditions and after lyophilization compared to that of PEI $25 \mathrm{kDa}$, due to the presence of many hydroxyl groups in the polymer backbone, which was also responsible for lowering the surface charge of the particles. The polymer consisted of ester-linkages as a degradable part and showed highly accelerated transfection activity compared to the PEI $25 \mathrm{kDa}$ and comparable to Lipofectamine with significantly less cytotoxicity. The most interesting was that the synthesized degradable polymer exhibited several fascinating transporter mechanisms which were responsible for higher transfection activity, not only due to degradability of the synthesized material, but also owing to introduction of osmotic active polysorbitol property to the degradable cross-linked LMW PEI [37]. They termed this novel gene carrier as a polysorbitol-based osmotic active transporter (PSOAT), where the mechanism studies elucidated that the polysorbitol linkages, introduced by cross-linking of SDM to LMW PEI, with polyvalent capacity showed accelerated transfection efficiency than the monovalent sorbitol. Moreover, the transfection activity of PSOAT was highly prevented by a COX-2-specific inhibitor (SC236) according to the inhibitor dose-dependent manner, suggesting that COX-2 might be involved in acceleration of the PSOAT-mediated gene transfer, since there were reports on hypertonicity-dependent coregulation of COX-2 activity with the organic osmolyte-dependent adaptation of cells to hyperosmotic stress, where COX-2 inhibition reduced organic osmolytes (such as sorbitol) uptake by the cells $[38,39]$. Furthermore, PEI also had synergistic effect on increasing the transfection activity of the transporter system with their buffering capacity [37].

3.1.2. Degradable Grafted PEIs. Extensive researches were conducted on synthesizing degradable grafted polymers 


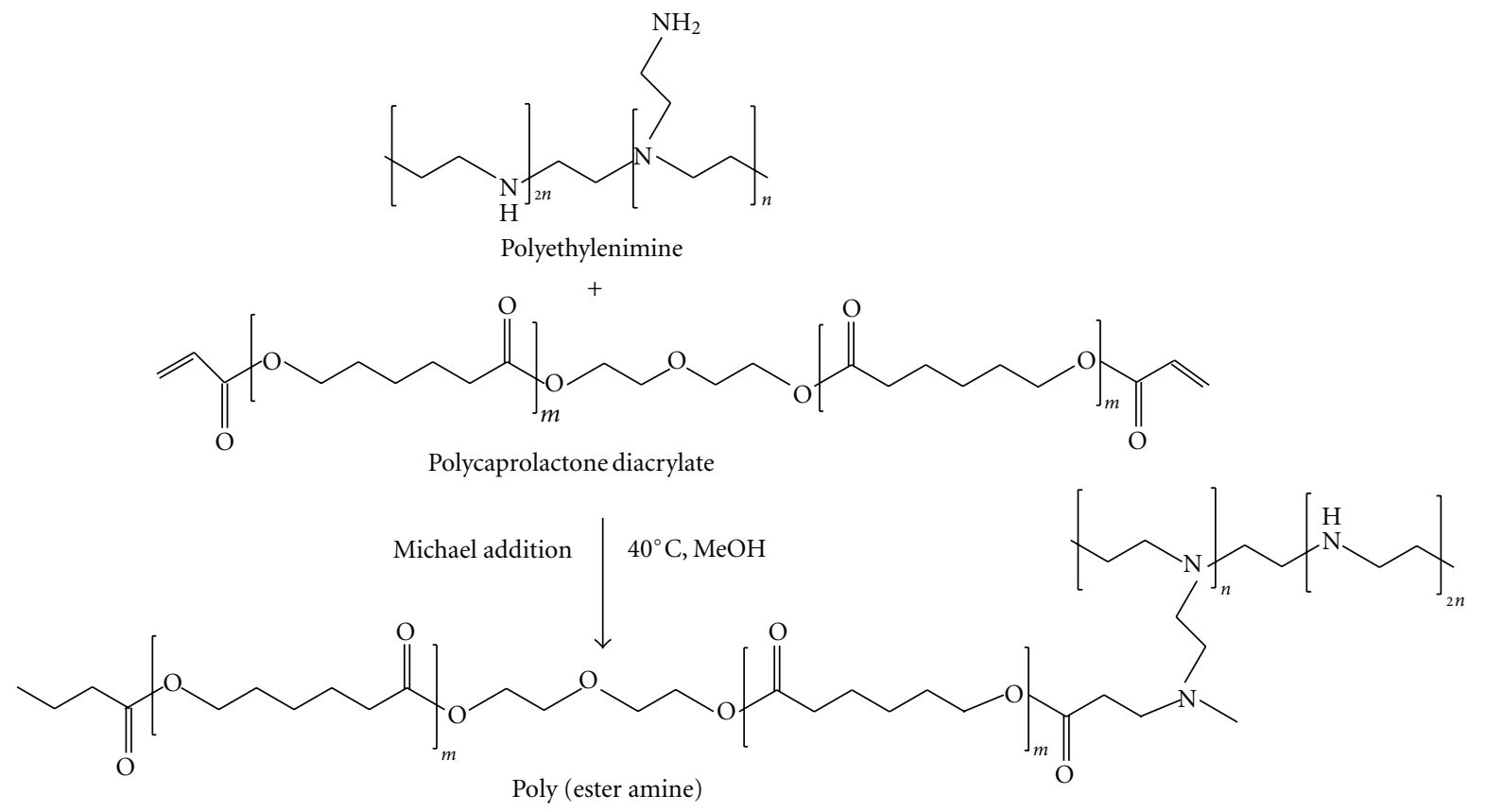

FIgURE 4: The synthetic scheme of PEA based on PEI and polycaprolactone diacrylate by Michael addition [35].

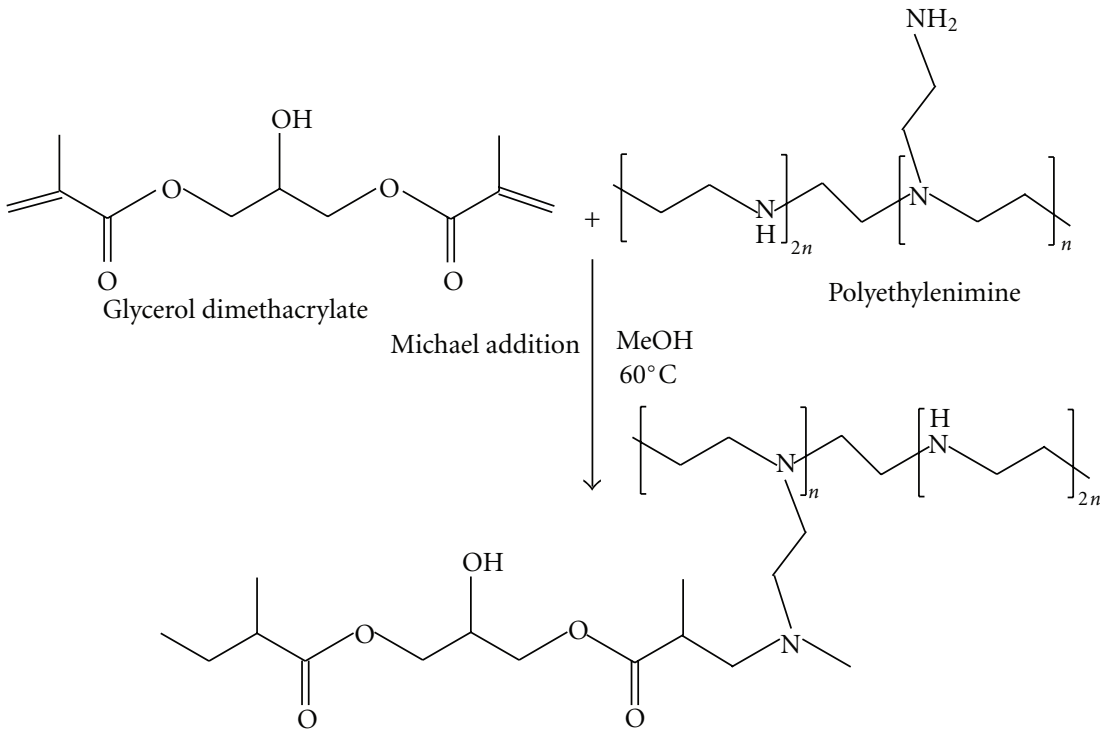

Poly (ester amine) prepared from GDM and PEI

FIGURE 5: Synthesis scheme of PEA based on glycerol dimethacrylate (GDM) and PEI. GDM linker reacts with primary and secondary amines of PEI resulting in formation of ester bonds [36].

based on linear or hyperbranched LMW PEIs to increase transfection activity and reduce cellular toxicity. Most of the studies applied degradable polymers such as chitosan, dextran, PCL, and polypropylenimine dendrimers as well as nonionic hydrophilic cyclodextrin (CD).

Pun and coworkers first reported the grafted PEI derivative synthesized from high MW PEI and CD for gene delivery purposes [40]. Tang et al. synthesized degradable grafted PEI based on $\beta$-CD-carbonate benzotriazole with LMW PEI
$(600 \mathrm{Da})$ through a polycondensation reaction [41]. The MW of the polymer reduced from 61 to $30 \mathrm{kDa}$ within 30 days in phosphate-buffered saline (PBS) (pH 7.0) at $37^{\circ} \mathrm{C}$, because of carbamate carbaryl hydrolysis in the grafted polymer, whereas their degradation in Tris-buffer was not obvious. In neuronal cells, the polymer showed enhanced gene transfection compared to PEI $25 \mathrm{kDa}$. Also they found comparable gene expression to PEI $25 \mathrm{kDa}$ after intrathecal injection of the complexes into spinal cord of rat [41]. In 

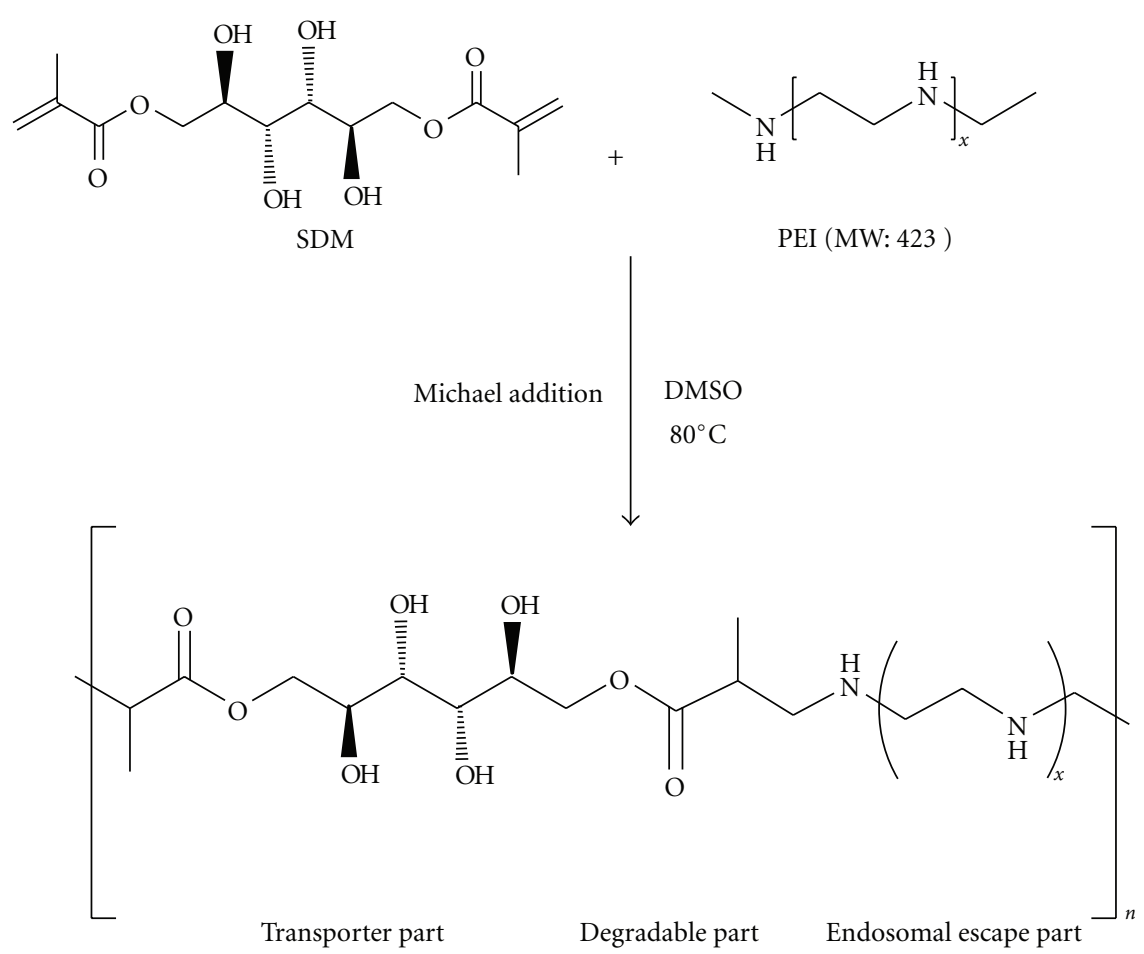

PSOAT prepared from SDM and PEI

FIgURE 6: Proposed reaction scheme for synthesis of PSOAT based on sorbitol dimethacrylate (SDM) and PEI [37].

another study, Yang et al. grafted CD as a grafted polymer to LMW PEI chains. The synthesized polymer was stable and protected from hydrolysis under physiological conditions owing to the urethane linkages in the polymeric arms. They effectively condensed DNA and showed higher transfection efficiency and safety compared to PEI $25 \mathrm{kDa}$ [42].

Chitosan has been studied extensively for many years as a nonviral carrier due to their less-toxic, biodegradable and biocompatible nature. However, one of the most important limitations for application of chitosan was their low transfection capability [43]. Giving eye on that PEI-graft-chitosan was synthesized through cationic polymerization of aziridine in the presence of water-soluble chitosan $(3400 \mathrm{Da})$ to obtain the combined properties of PEI with proton-sponge effect for increasing transfection activity and of chitosan with biocompatible and degradable characteristics for reducing the toxicity [44]. The synthesized grafted degradable PEI provided higher transfection efficiency and safety compared to the control PEI $25 \mathrm{kDa}$ in various cell lines because of the PEI and chitosan function, respectively. Moreover, the grafted polymer exhibited 58-fold higher transfection activity than that of PEI $25 \mathrm{kDa}$ in liver after delivery into the bile-duct in rat liver [44]. In another recent report, chitosan-graft-PEI was synthesized by Jiang et al. through the reaction between LMW PEI (1800 Da) and periodateoxidized chitosan as shown in Figure 7. The grafted polymer showed good DNA binding as well as protection ability with higher transfection efficiency and safety [45].

Lou et al. also used a short PEG-linker (440 Da) with the terminal epoxide rings in the synthesized PEI-graft-chitosan to reduce the cytotoxicity of the grafted PEI carrier. The polymer showed a significantly high cell survival and gene expression than that of chitosan itself in 293T cells [46]. Another report showed the use of $N$-maleated chitosan to graft PEI for synthesis of PEI-graft- $N$-maleated chitosan carrier for gene delivery. The grafted polymer showed low toxicity and high gene expression in 293T and HeLa cells; however, a high toxicity and low transfection activity was observed by the high MW polymer than the LMW one [47].

As a biodegradable natural polysaccharide, dextran has been a handy polymer for gene delivery application, because they can be enzymatically digested in the physiological conditions and would favor reduction of toxic effects and increase of transfection. Dextran-graft-PEI, synthesized through grafting the LMW PEI (800 Da) using hexamethylene diisocyanate modified dextran, showed high transfection ability with lower toxicity compared to the PEI $25 \mathrm{kDa}$-mediated gene carrier, although these depend on MW of dextran, where the LMW dextran was beneficial to increase gene expression and reduce cellular toxicity than the high MW one [48]. The same groups also tried with carboxymethyl dextran, another dextran derivative to 


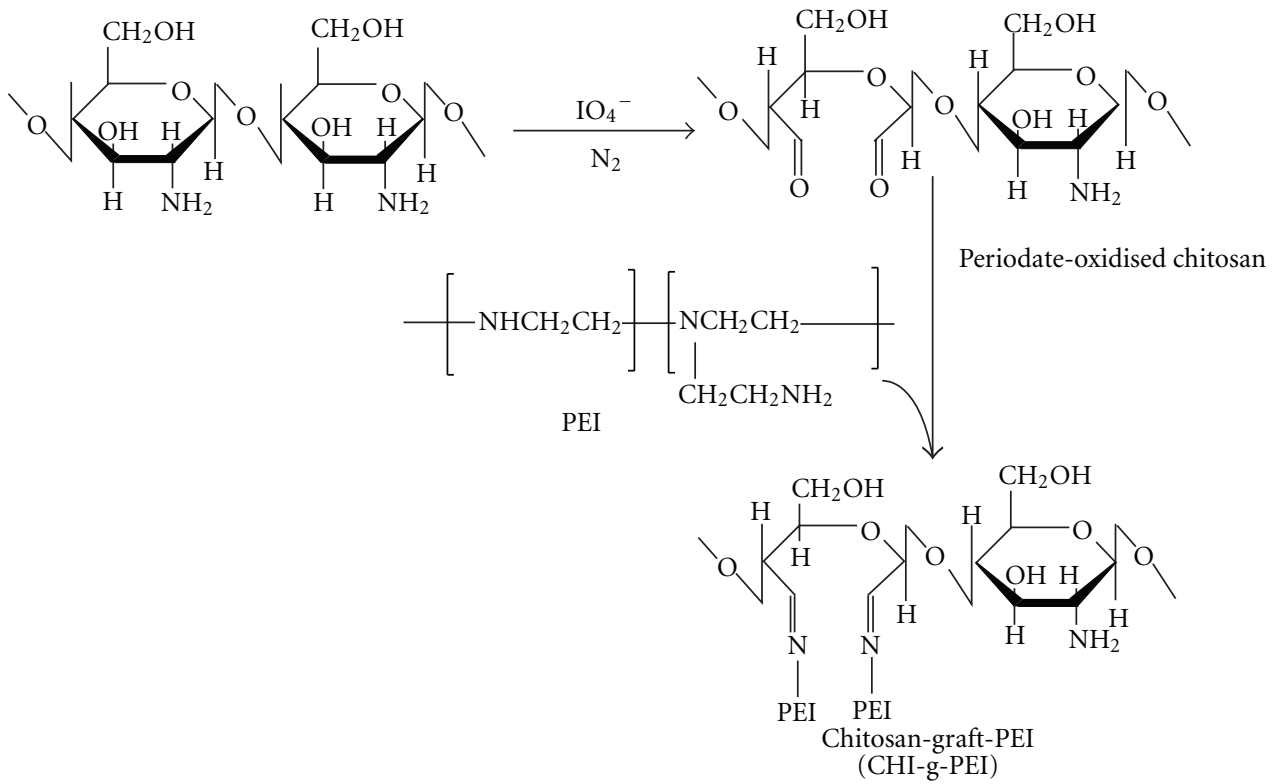

Figure 7: Proposed reaction scheme for synthesis of CHI-g-PEI [45].

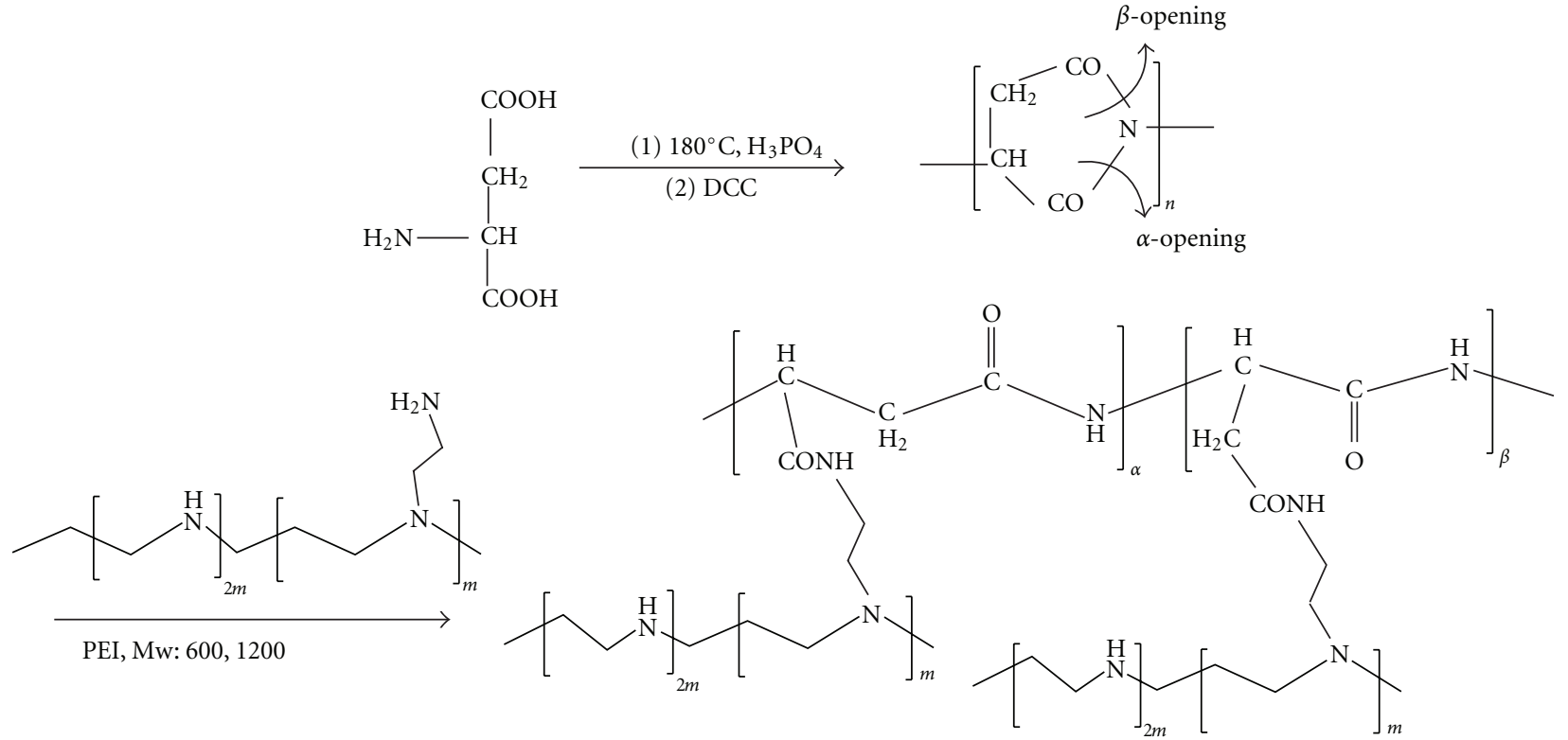

Figure 8: The synthesis scheme of Asp-g-PEI [51].

graft the LMW PEI (800 Da) and found enhanced gene transfection capability and to lower cytotoxicity of the carrier [49]. It is interesting to be noted that among the studies of chitosan and chitosan derivatives-mediated grafting of PEI, the enhanced transfection activity with low toxic effects were achieved through the LMW PEI than the high MW one.

Zhang et al. grafted LMW PEI using $1,1^{\prime}$ carbonyldiimidazole as a carbamate linkage into the main chain of PEG-dithiothreitol (DTT) by Michael addition reaction between DTT and PEG diacrylate, because degradation of carbamate linkage will produce alcohol, $\mathrm{CO}_{2}$, and amino groups. Because of having degradable carbamate linkage, the polymer exhibited higher gene expression capability with low cellular toxicity in various cell lines, including HeLa, HepG2, MCF-2, and COS-7 cells [50]. Yu et al. grafted LMW linear (423 Da) as well as branched PEI (600 and 1,200 Da) to polyaspartate by the ring opening reaction of poly (Lsuccinimide) as shown in Figures 8 and 9, respectively [51, 52]. The cytotoxicity of the branched PEI-grafted polymer was higher than that of the linear PEI-grafted one, thus exhibited lower transfection, suggesting that linear PEI is more tolerable than branched one. 

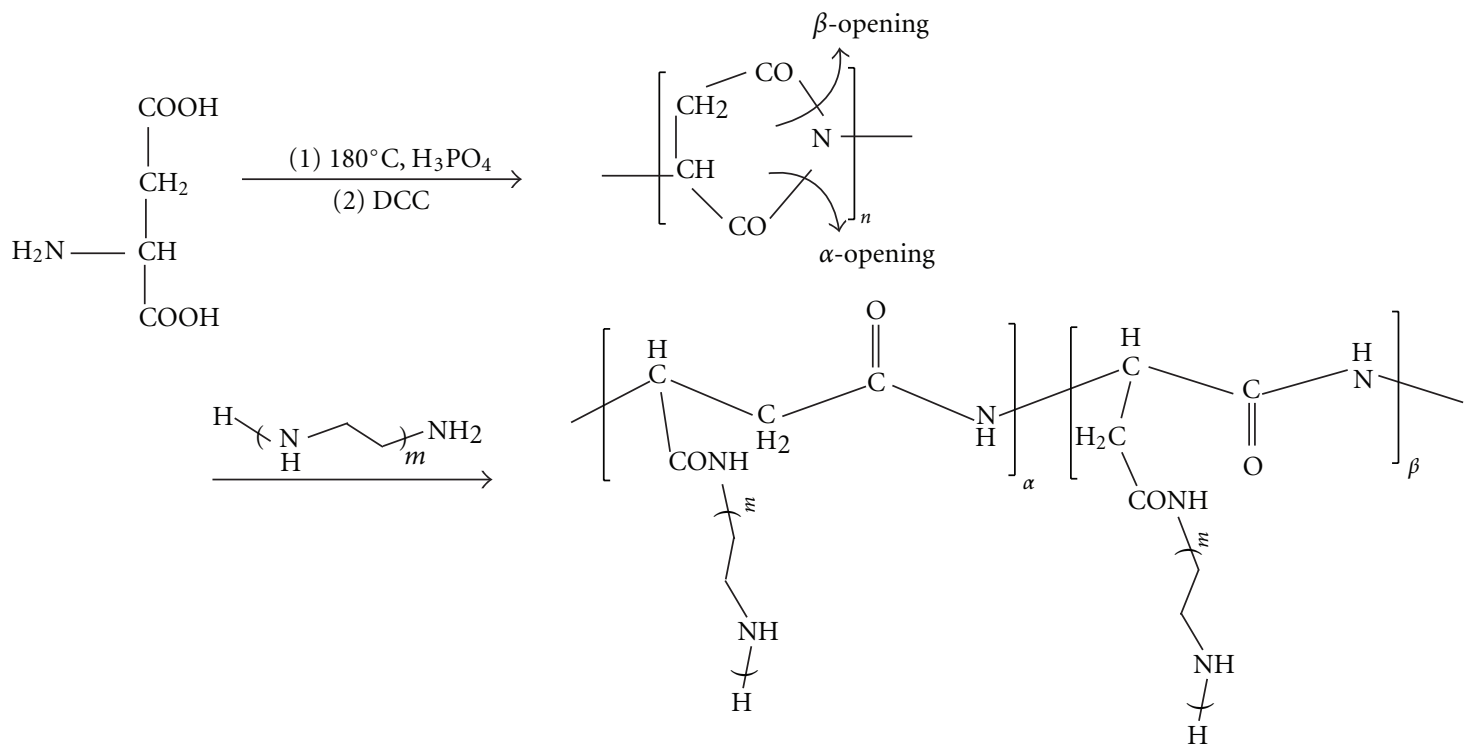

Figure 9: The synthesis scheme of PEA based on PEI and poly (L-succinimide) [52].

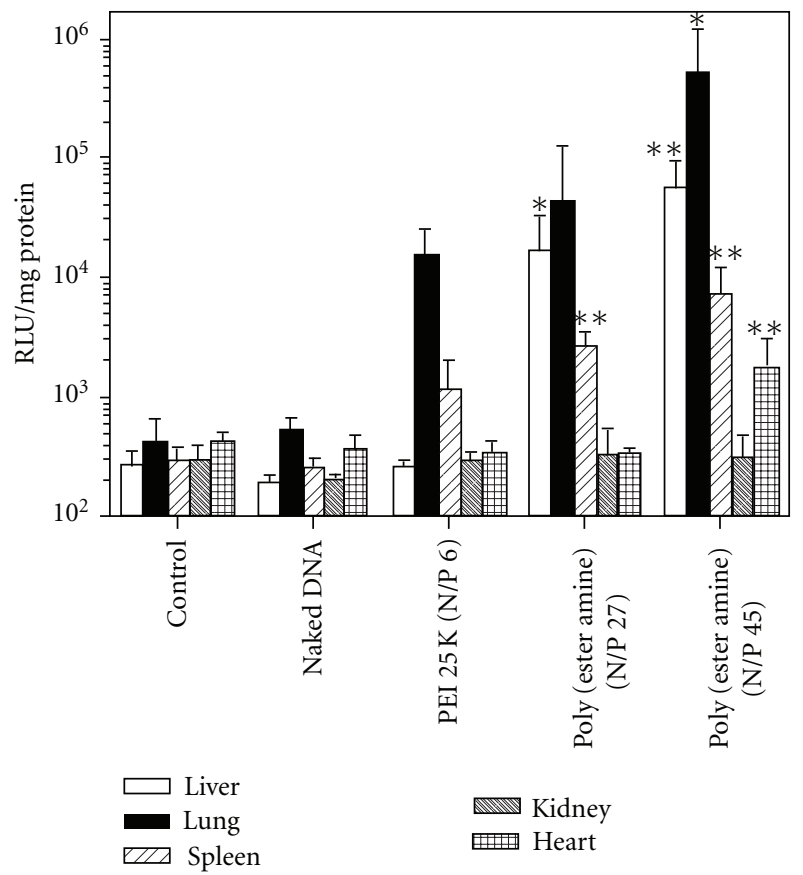

(a)

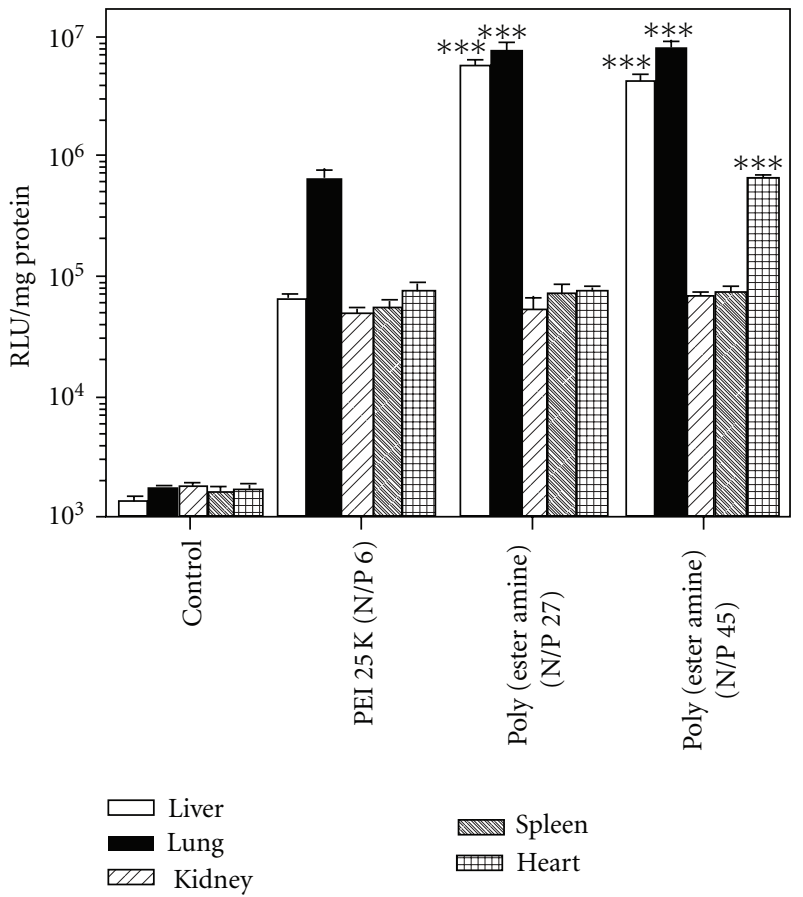

(b)

Figure 10: Tissue distribution of PEA/DNA (gWIZ-Luc) complexes administered by intravenous injection and inhalation at various N/P ratios. ( ${ }^{*} P<0.1 ;{ }^{* *} P<0.05 ;{ }^{* *} P<0.01$, Student's $t$-test, two-tailed): (a) intravenous injection $(n=4$, error bars represent standard deviation) and (b) aerosol administration ( $n=4$, error bars represent standard deviation). Note that there was two mice dead among four mice due to the toxicity in the PEA/DNA complex at N/P 45 of intravenous injection; no toxicity was observed in all the other groups [53].

3.2. Degradable PEIs according to Degradable Linkages. The degradable PEIs can be mainly classified into ester, disulfide, imine, carbamate, amide, and ketal linkages as the degradable parts.

3.2.1. Ester Linkages. The degradable PEIs having ester linkage can be obtained by simple Michael-type addition reaction between LMW PEI and diacrylate as a cross-linker. The prepared degradable PEIs having ester linkages are easily degradable through hydrolysis mechanism. They have low cytotoxicity with high transfection efficiency owing to the degradation of the ester linkages and $\mathrm{pH}$ buffering capacity by PEI. Some of degradable PEIs with ester linkage were also included in Section 3.1. Degradable PEIs were obtained 


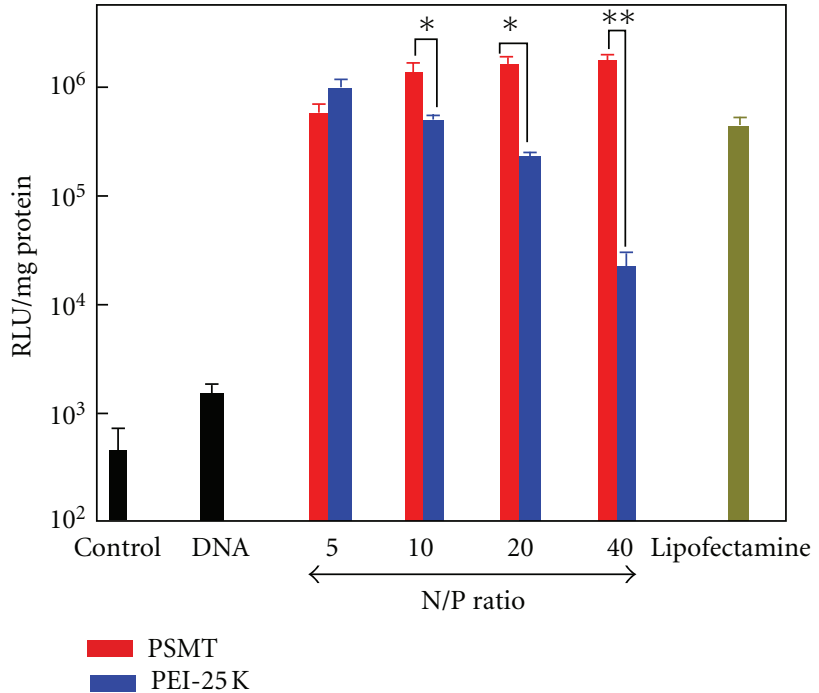

(a)

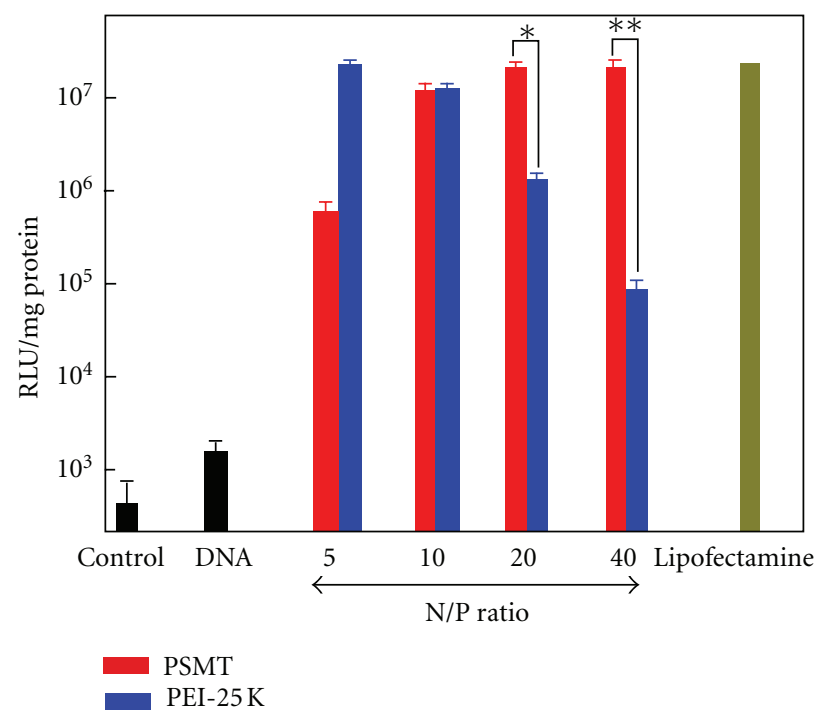

(c)

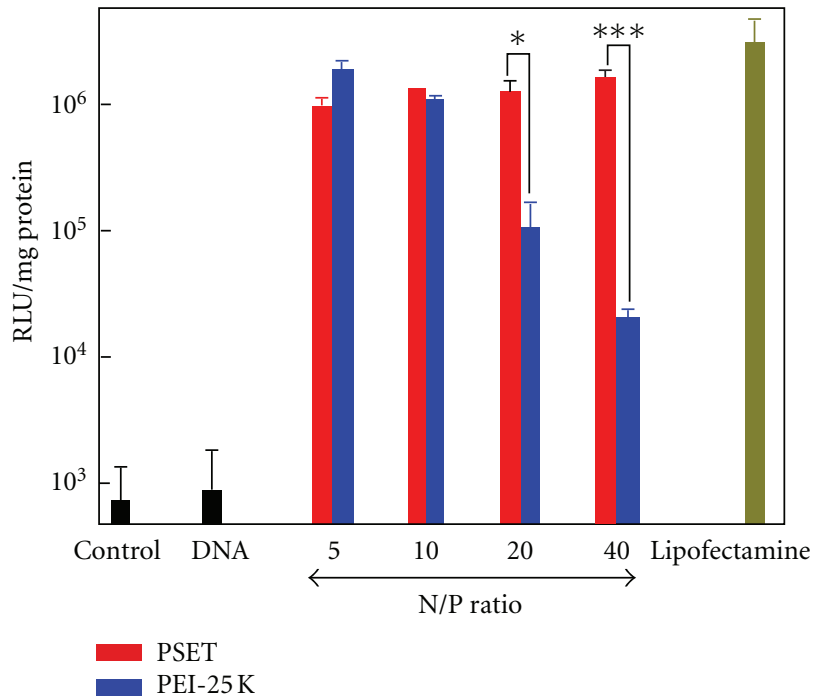

(b)

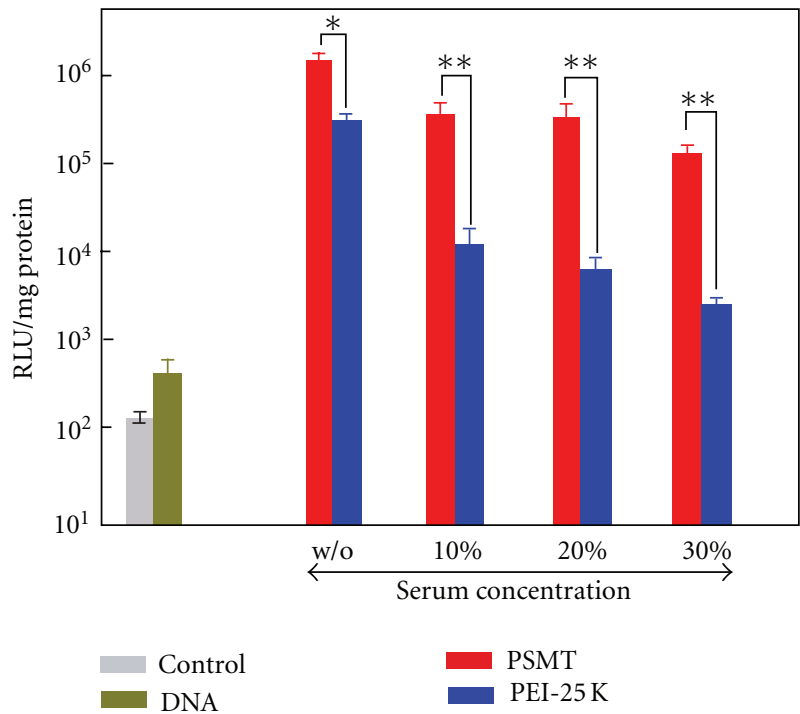

(d)

Figure 11: Luciferase activity of PSMT/DNA and PEI 25K/DNA complexes at various N/P ratios in serum-free medium (a), (b), (c) with A549 (a), HeLa (b), 293T (c) cell lines and effect of serum on transfection efficiency of PSMT/DNA (N/P 20), and PEI 25K/DNA (N/P 5) complexes in A549 cell line (d) $\left(n=3\right.$, error bar represents standard deviation, ${ }^{*} P<0.05, * * P<0.01$, ${ }^{* * *} P<0.005$, one-way ANOVA) [55].

by Michael addition reaction between LMW PEI (423 Da) and PEG diacrylate by Park et al. [53]. The half-life of the polymer with MW of 258 in PEG diacrylate was longer than that of the polymer prepared by 1,3-butanediol diacrylate due to the higher MW of diacrylate. The transfection efficiency of the polymer in MG63 cells was higher than that of PEI $(25 \mathrm{kDa})$ with lower cytotoxicity. Also transfection efficiency in various organs of mice between intravenous (IV) administration and aerosol one using this polymer was compared [53]. The polymer showed high transfection efficiency in all of mice organs than PEI $(25 \mathrm{kDa})$ in both routes of administration owing to the lower cytotoxicity. Interestingly, aerosol administration as a local delivery showed much higher transfection efficiency in lung than IV one as a systemic delivery due to easy access to pulmonary tissues through aerosol delivered first pass effect as shown in Figure 10 [53]. Furthermore, they prepared degradable PEIs based on PEG dimethacrylate and LMW PEIs $(600,1200$, and $1800 \mathrm{Da}$ ) by the same Michael-addition reaction [54]. The polymer showed comparative transfection efficiency in 293T, HeLa, and HepG2 cells compared to PEI (25 kDa) and the gene expression of the polymer was increased with increasing the MW of starting PEIs owing to the increased proton sponge effect with an increase of MW of PEI.

Recently, Luu et al. prepared degradable PEIs having ester linkage based on osmotic sorbitol diacrylate [55] or 


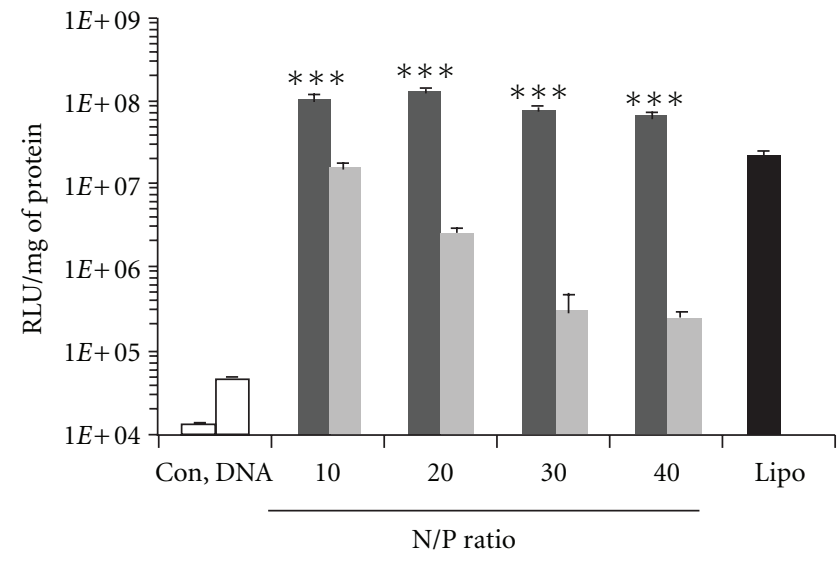

(a)

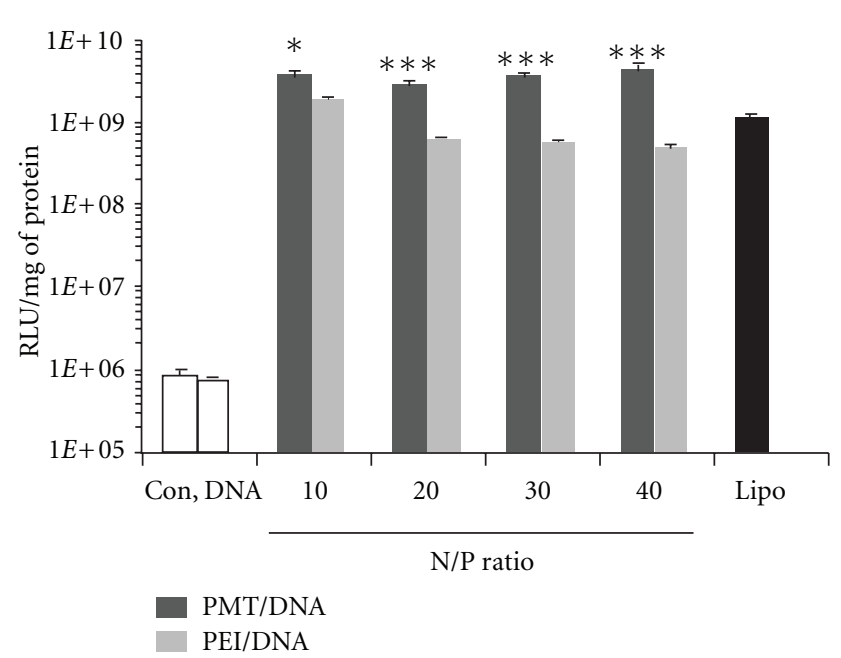

(c)

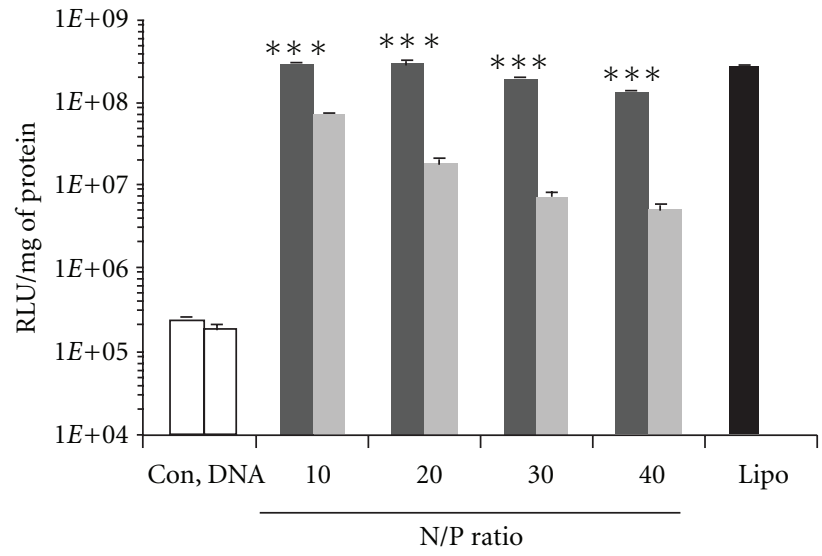

(b)

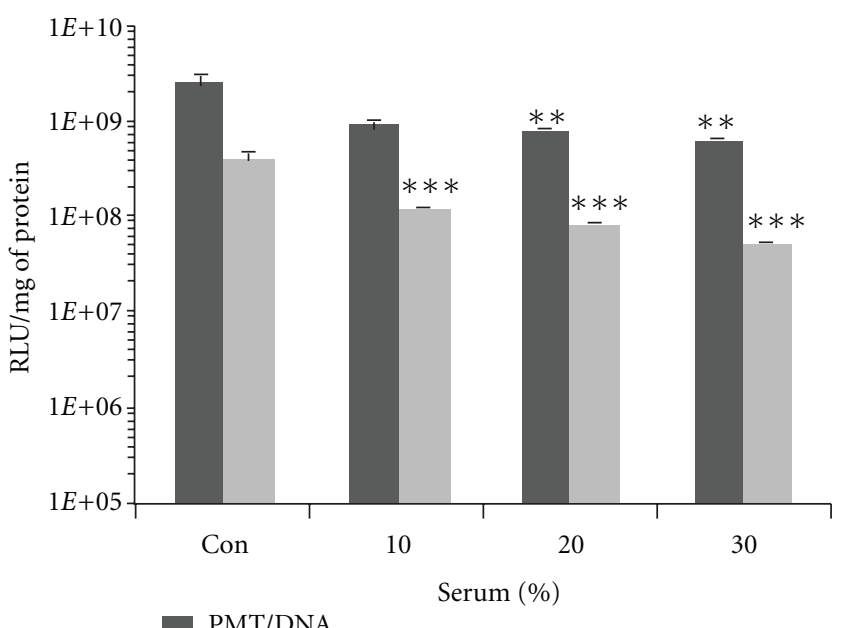

PEI/DNA

(d)

FIGURE 12: In vitro transfection efficiency of PMT/DNA complexes with or without serum. The same amount of pGL3 plasmids were complexed with PMT, PEI, and Lipofectamine 2000 and delivered to (a) A549 cells, (b) N2a cells, and (c) HeLa cells without serum. (d) The PMT and PEI/pGL3 complexes were transfected in A549 cells in the presence of various amount of serum. Luminescence was measured $24 \mathrm{~h}$ after transfection and normalized with the amount of protein. $\left(n=3\right.$, error bar represents standard deviation; ${ }^{*} P<0.1,{ }^{* *} P<0.05$, *** $P<0.01$, one-way ANOVA compared to that of PEI/DNA complexes (a)-(c) and control (d)) [56].

mannitol diacrylate [56] with low MW PEI (1,200 Da) via a Michael addition reaction. The polysorbitol-mediated transporter showed higher transfection efficiency in three different cell lines (A549, HeLa, and 293T cells) than PEI $(25 \mathrm{kDa})$ by regulation of selective caveolae endocytosis pathway as shown in Figure 11 [55] by hyperosmotic polysorbitol despite the existence of PEI composition in the polymer. Also the polymannitol-based gene transporter as shown in Figure 12 showed higher transfection efficiency in A549, HeLa, and N2a cells with lower cytotoxicity than PEI $(25 \mathrm{kDa})$ and selectively stimulated caveolae-mediated endocytosis by hyperosmotic polymannitol. The shifting of polyplexes into caveolae-mediated endocytosis avoided lysosomal degradation of gene and introduced phosphorylation of caveolin-1 through Src-kinase [56]. The characteristics of degradable PEIs having ester linkage are summarized in Table 1.
3.2.2. Disulfide Linkage. The disulfide linkage as redoxsensitive bond can be cleaved in the presence of reducing enzyme such as glutathione reductase or glutathione [57]. Since glutathione concentration in the cytoplasm (0.5$10 \mathrm{mM})$ is much higher than in the plasma $(2-20 \mu \mathrm{M})$, the disulfide bond can be rapidly degraded in the intracellular environment whereas the bond is relatively stable in the extracellular environment [58]. Therefore, many disulfidecontained polymeric gene carriers have been developed. Some of degradable PEIs with disulfide linkage were also explained in Section 3.1.

Bauhuber et al. prepared a library of PEG-PEI diblock copolymer having disulfide bond between PEG block and PEI one and studied a structure-function relationship of the polymers [59]. The results indicated that the PEG content was higher than $50 \%$ and had a greater effect on the physicochemical properties of the polyplexes than PEI 


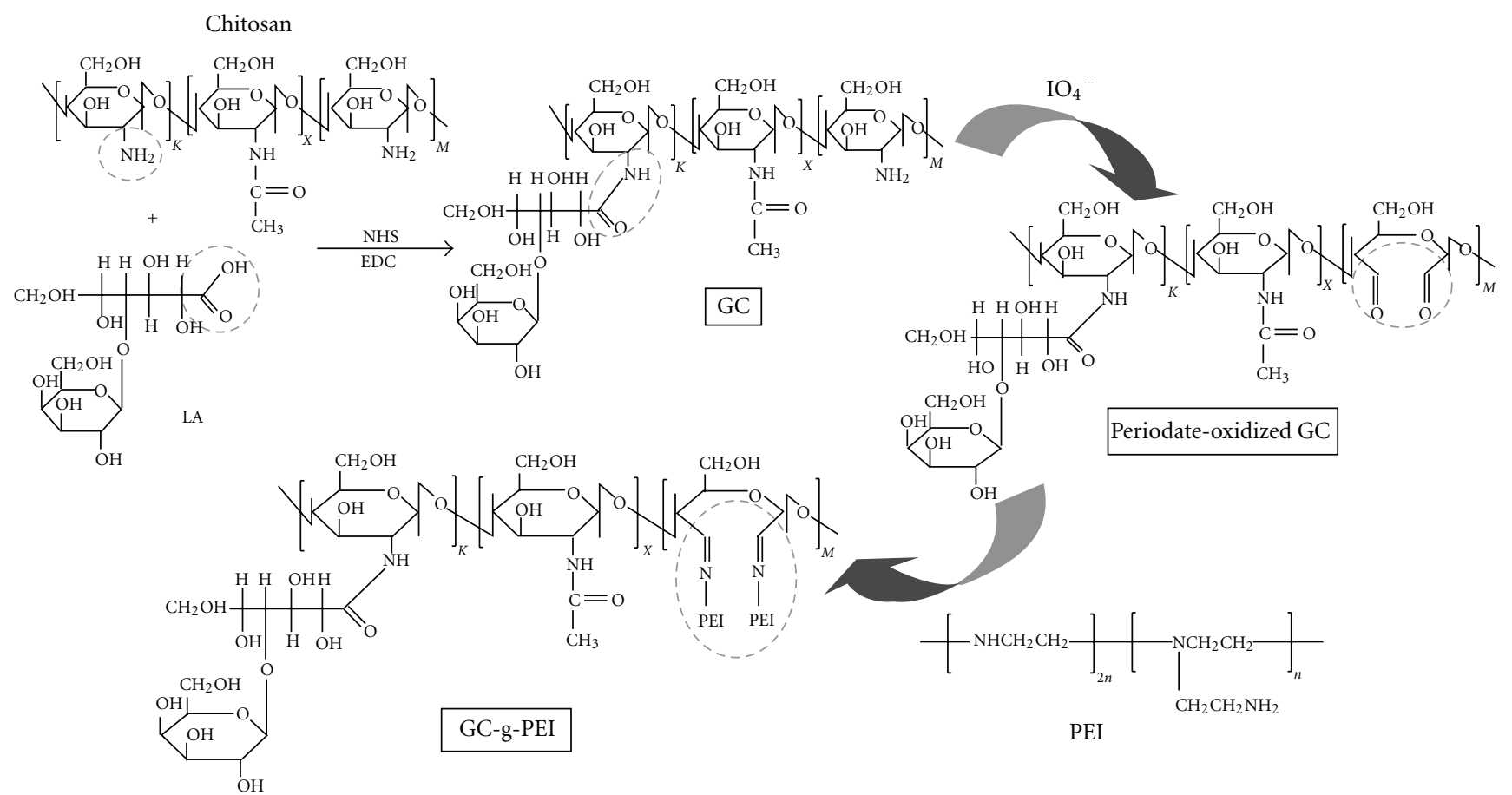

FIGURE 13: Proposed reaction scheme for synthesis of galactosylated chitosan-graft-polyethylenimine (GC-g-PEI) [74].

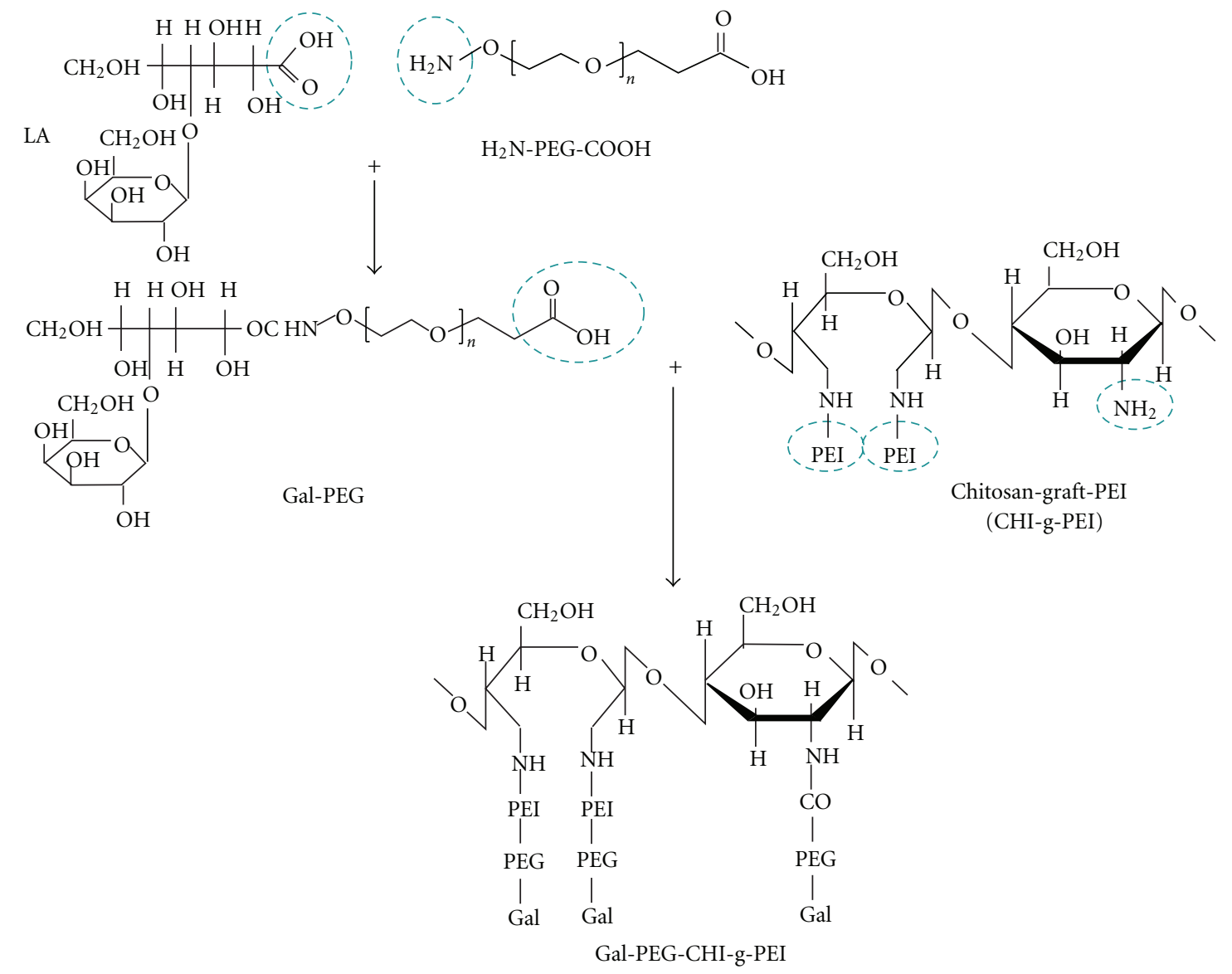

FIGURE 14: Proposed reaction scheme for synthesis of Gal-PEG-CHI-g-PEI [75]. 


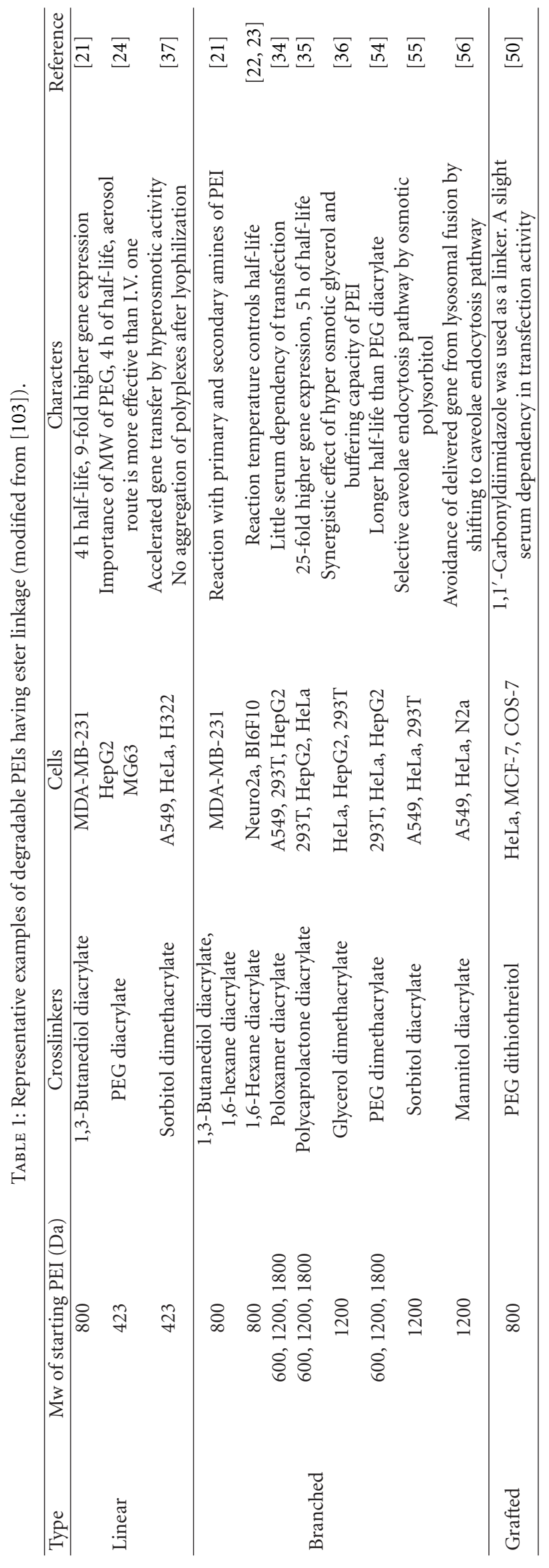




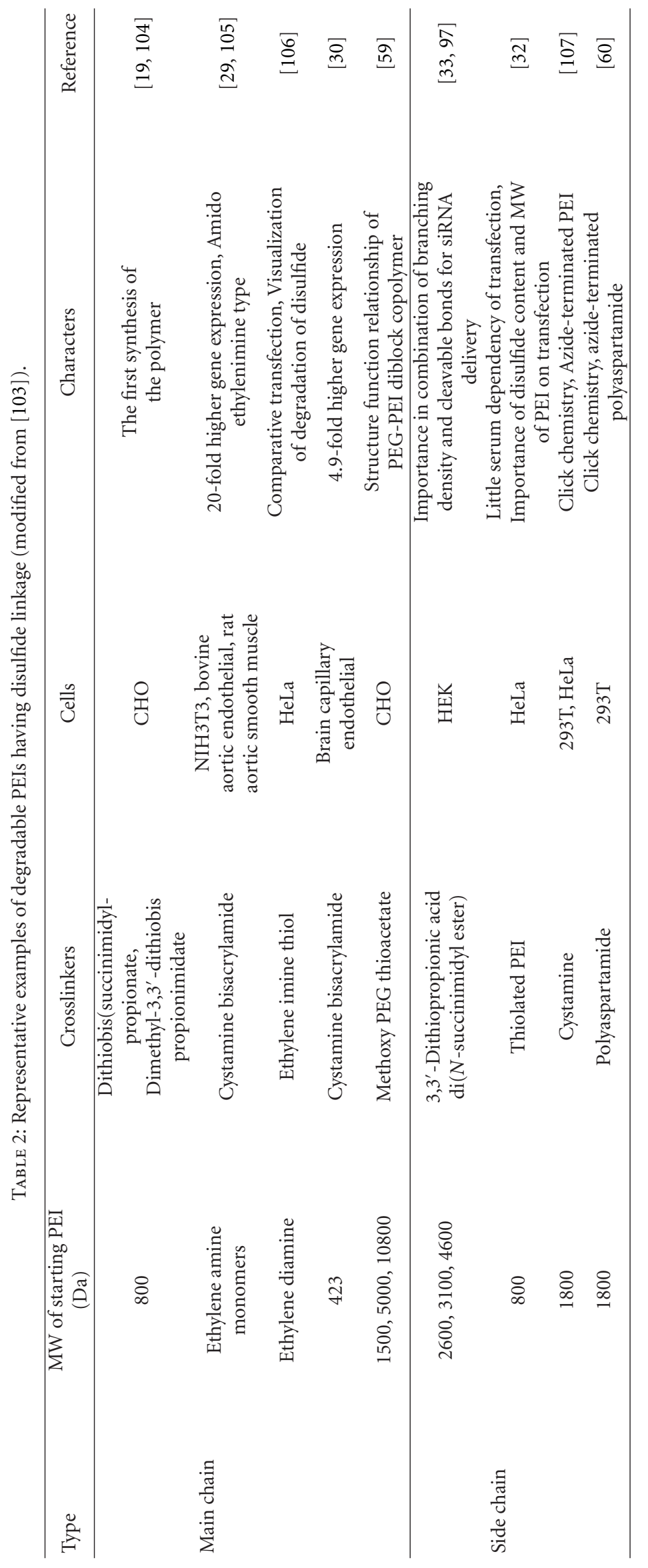



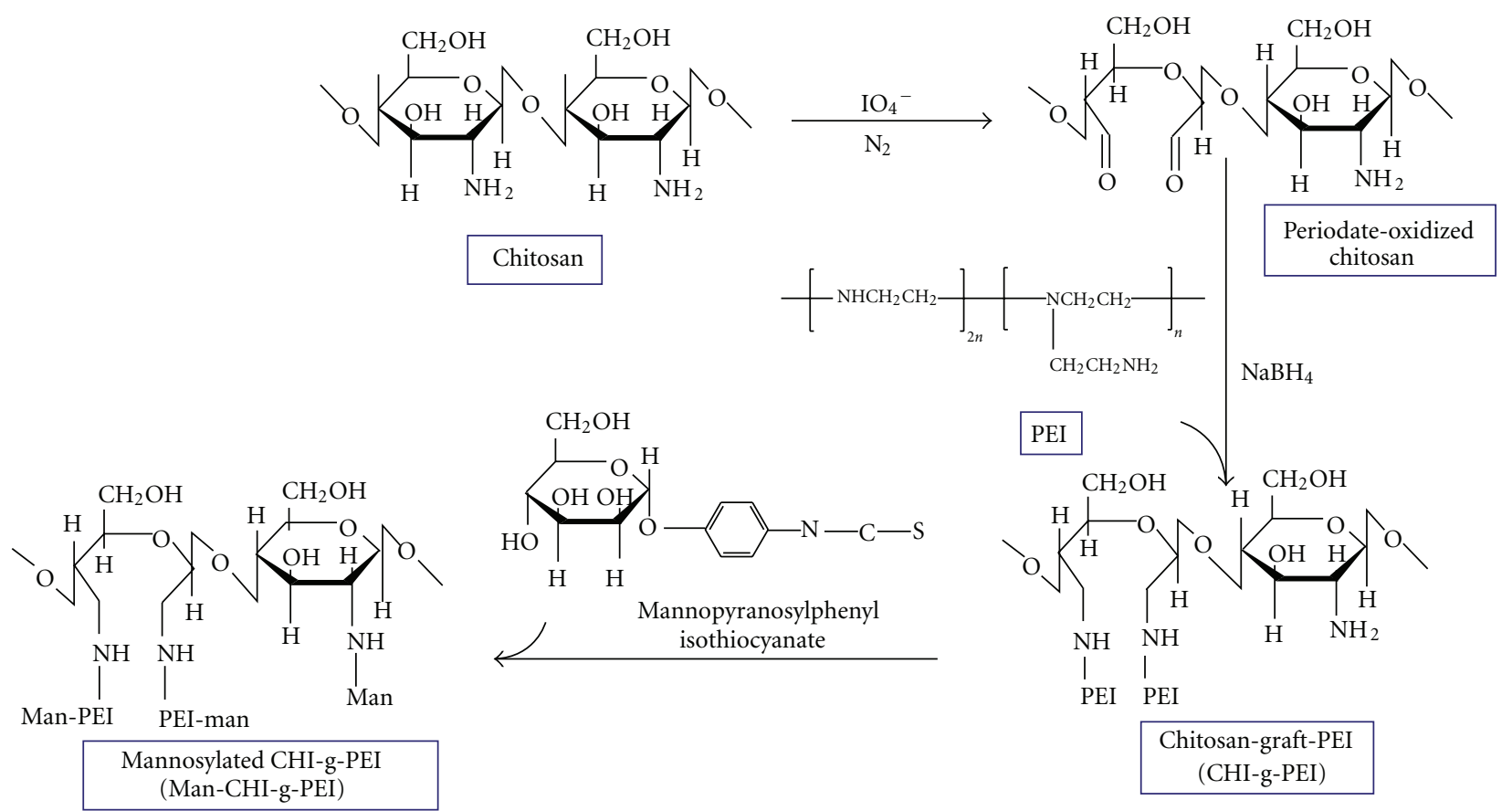

FIgURE 15: Proposed reaction scheme for synthesis of Man-CHI-g-PEI [78].

although the transfection efficiency of these polymers was significantly reduced compared to the PEI $(25 \mathrm{kDa})$ and it was restored by the redox triggerable PEG domain.

Recently, Zhang et al. prepared polyaspartamide-based disulfide-containing brushed PEI by click chemistry because the click chemistry has become a very popular technique for polymer synthesis owing to the high selectivity and fidelity [60]. The polymer showed higher transfection activity with lower cytotoxicity than PEI $(25 \mathrm{kDa})$ both in the presence and absence of serum due to the reduction-sensitivity of the polymer in the intracellular environment. The characteristics of degradable PEIs having disulfide linkage are summarized in Table 2.

3.2.3. Imine Linkage. Imine linkage can be synthesized by nucleophilic addition from an aldehyde or ketone and amine. But the imine linkage can be hydrolysed with water and more rapidly hydrolysed to the corresponding amine and carbonyl compound at the acid condition. Also, the imine can be reduced to an amine by the reducing agent.

Kim et al. prepared degradable PEI by reaction of glutaraldehyde and LMW PEI (1800 Da) with acid-labile linkages [28]. The polymer showed comparable transfection efficiency in 293T and A7R5 cells with lower cytotoxicity due to the rapid degradation of imine linkage with a halflife of $1.1 \mathrm{~h}$ at $\mathrm{pH} 4.5$. Many researchers have prepared degradable PEIs with imine linkage by reaction of chitosan and LMW PEI because the limitation of low transfection efficiency of chitosan can be overcome by buffering capacity of PEI in the prepared polymer. Ping et al. prepared chitosangraft-(PEI- $\beta-C D)$ via reductive amination between oxidized chitosan and LMW PEI-modified $\beta$-CD with imine linkage for DNA and siRNA delivery [61]. The polymer showed higher transfection efficiency in HEK293, L929, and COS7 cells than PEI $(25 \mathrm{kDa})$ with both time- and dose-dependent manners. Also the polymer showed superior knockdown effect by siRNA in HEK293 and L929 cells with lower cytotoxicity. Furthermore, the pendent $\beta$-CD in the polymer allowed the supramolecular PEGylation to improve stability of the polyplexes under physiological conditions.

Recently, Jiang and Salem prepared dextran-graft-PEI by reaction of dextran and LMW PEIs (800 and $2000 \mathrm{Da}$ ) as a similar method of chitosan-graft-PEI having imine linkage because dextran is also a biocompatible polysaccharide [62]. The polymer showed moderately lower transfection efficiency in HEK293 cells than PEI $(25 \mathrm{kDa})$ when the transfection was carried out in media without serum for $4 \mathrm{~h}$ whereas the polymer showed significantly higher transfection efficiency when the incubation time of the vectors in the presence of serum was increased to $48 \mathrm{~h}$ with lower cytotoxicity due to the improved stability in serum containing conditions. Some of degradable PEIs with imine linkage were also included in Section 3.1.

3.2.4. Carbamate Linkage. Carbamate is derived from carbamic acid. The carbamic acid is often chemically interconverted to the carbamate ester such as urethane. Therefore, the carbamate linkage is relatively stable.

Ahn et al. prepared degradable PEI by a reaction of PEG succinimidyl succinate and LMW PEI $(600,1200$, and $1800 \mathrm{Da}$ ) via carbamate linkage [27]. The polymer exhibited 3 -fold higher transfection efficiency in 293T than starting LMW PEI, while the cell viability was maintained over $80 \%$ although the transfection efficiency of the polymer was lower 


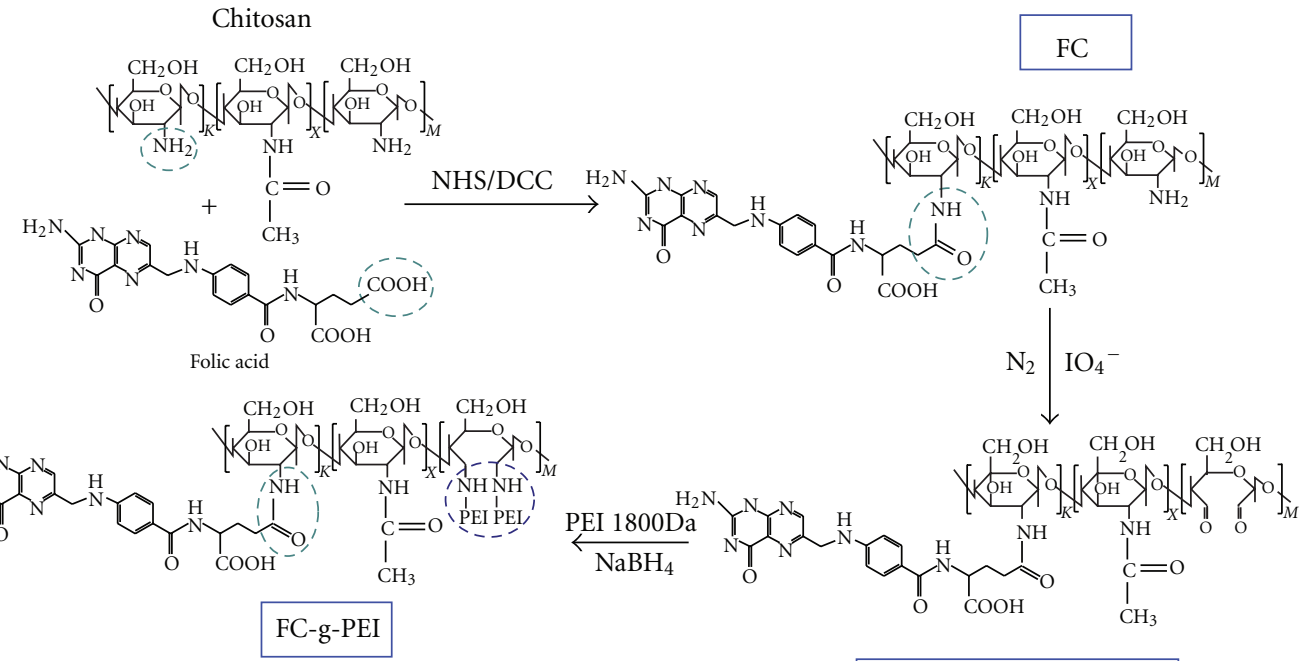

(a)

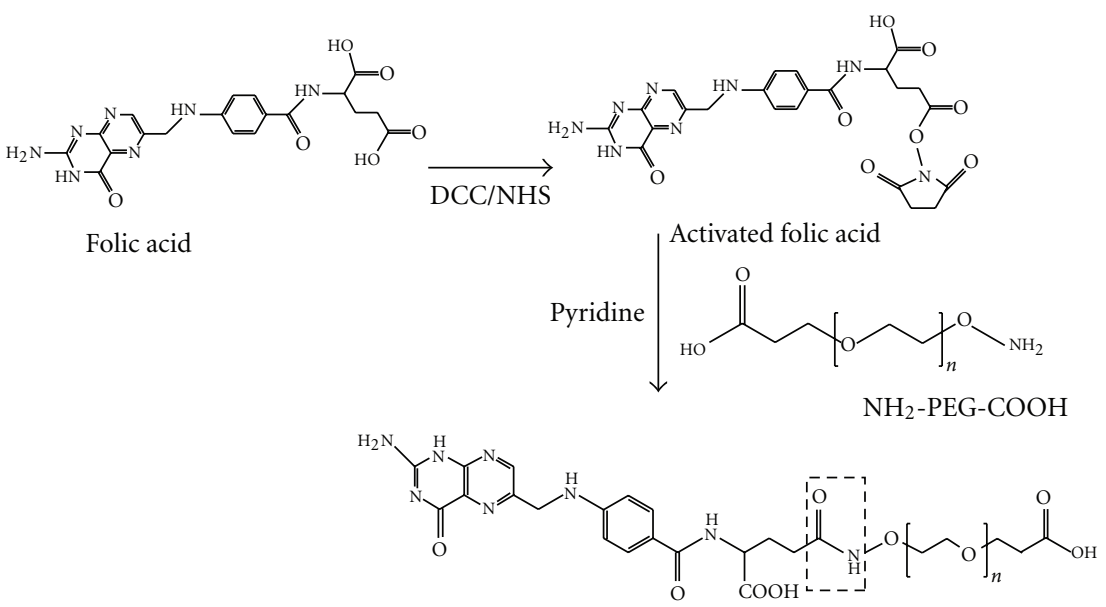

Folate-PEG

Periodate-oxidized FC

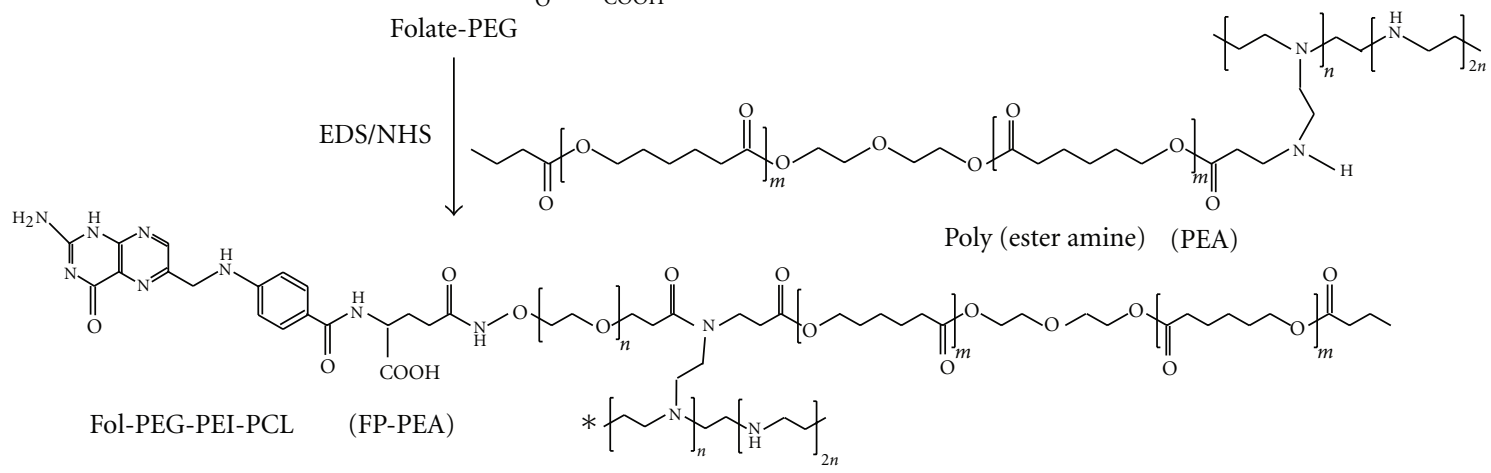

(b)

FIGURE 16: (a) Proposed reaction scheme for synthesis of FC-g-PEI [80]. (b) Synthesis scheme of FP-PEA. FA was activated using DCC/NHS chemistry to which bifunctional PEG was coupled resulting in formation of amide bond [81].

than PEI $(25 \mathrm{kDa})$ probably due to hydrophilic nature of PEG.

$\mathrm{Xu}$ et al. prepared degradable PEI by a reaction of 1,4butanediol bis (chloroformate) and LMW PEI ( $800 \mathrm{Da})$ via carbamate linkage [63]. The polymer exhibited remarkably higher transfection activity in MeWo cells as compared with PEI $(25 \mathrm{kDa})$ although molecular weight of obtained polymer is not much high $(\mathrm{MW}=2,800 \mathrm{Da})$. Liu et al. synthesized poly (ester-co-urethane)-PEI conjugate as the degradable PEI through aminolysis of poly (ester-courethane) by LMW PEI ( $800 \mathrm{Da}$ ) [64]. The polymer has two degradable linkages: one is ester bond in the main chain 
and the other is carbamate one in the side chain. Also this polymer showed higher gene expression in COS7 cells than PEI $(25 \mathrm{kDa})$ with lower cytotoxicity due to degradation with a half-life of $14 \mathrm{~h}$ at $\mathrm{pH} 7.4$.

Zhao et al. compared transfection efficiency in vitro and in vivo between degradable PEI based on glutaaldehyde and LMW PEI (2,000 Da) having imine linkages and degradable PEI based on activated triethylene glycol and LMW PEI (2,000 Da) having biscarbamate linkages [65]. The results indicated that PEI having acid-labile imine linkages exhibited higher transfection ability than PEI having biscarbamate ones although the mechanism is not clear. Recently, Wang et al. prepared degradable PEI by reaction of ethylene bis (chloroformate) and LMW PEI (800 Da) via biscarbamate linkages [66]. The polymer exhibited higher transfection efficiency in three different cells (COS7, BRL$3 \mathrm{~A}$, and HeLa cells) than PEI $(25 \mathrm{kDa})$ with low cellular toxicity.

3.2.5. Amide Linkage. Generally amide linkage is more stable to hydrolytic degradation than ester linkage at physiological conditions.

Xiong et al. synthesized poly (aspartate-graft-PEI 800) by grafting LMW of PEI ( $800 \mathrm{Da})$ to a polyaspartate backbone obtained by ring opening polymerization of $\beta$-benzyl Laspartate $N$-carboxyanhydride via amide linkage [67]. The polymer induced inflammation as well as apoptosis and necrosis in the liver and spleen of rodents at $24 \mathrm{~h}$, whereas the polymer did not show tissue damage or apoptosis by day 5. Also the optimized polymer showed higher transfection activity than PEI $(25 \mathrm{kDa})$ due to the decreased cell toxicity.

$\mathrm{Lu}$ et al. grafted LMW PEI (800 Da) to $N$-succinyl chitosan via amide linkages [68]. The polymer exhibited higher transfection efficiency in three different cell lines (293T, HeLa, and CHO cells) than PEI (25 kDa) with lower cytotoxicity although the toxicity increased with increasing grafting degree of PEI. Also the transfection efficiency was not affected in the presence of serum owing to hydroxyl groups in the chitosan. Wen et al. synthesized PEGb-polyglutamine-g-PEI by aminolysis of PEG-b-poly $(\gamma$ benzyl-L-glutamate) obtained through ring opening polymerization of $\gamma$-benzyl-L-glutamate $N$-carboxyanhydride by amine-terminated PEG using LMW PEI (423 Da) [69]. The polymer showed markedly higher transfection efficiency in four different cell lines (HeLa, HepG2, Bel9402, and 293T cells) with lower toxicity and the polymer was degraded in papain solution due to the amide linkages. Also the presence of serum did not affect the transfection efficiency due to the brush effect of PEG in the copolymer.

Namgung et al. prepared degradable star-shaped copolymers based on multi-arm PEG succinimidyl succinate (3arm and 6-arm) and LMW PEI (2.5 kDa) via amide linkages [70]. The polymer having 6-arm PEG exhibited higher transfection activity in three different cell lines (HeLa, NIH3T3 and PC-3 cells) than 3-arm-containing PEG in the polymer due to higher charge density and prevention of unwanted aggregation of the polyplexes obtained by 6 -arm polymer than 3-arm one.
Yu et al. grafted linear LMW PEI to poly (L-succinimide) (PSI) obtained by polycondensation of L-aspartic acid via amide linkages as shown in Figure 9 [52]. The polymer showed significantly higher transfection ability in three different cell lines (HeLa, 293T, and HepG2 cells) with lower toxicity because a brush-like polycation resulted from the high grafting degree of PEI to polyaspartate formed coreshell nanoparticles with hydrophilic shell and resulted in serum-resistant ability after transfection. They also grafted branched LMW PEI (600 and $1200 \mathrm{Da}$ ) to the PSI as a similar method with linear LMW PEI via amide linkages [51]. The polymer showed slightly higher transfection activity in HeLa, 293T, and HepG2 cells with lower cytotoxicity than PEI $(25 \mathrm{kDa})$ and the transfection efficiency decreased as the MW of the parent PEI increased due to increased charge density and toxicity of PEI.

3.2.6. Ketal Linkage. At mild acidic $\mathrm{pH}$ such as $\mathrm{pH}$ 5.0, ketal linkage is highly labile and causes release of DNA from the acidic endosome as well as lysosome into the cytoplasm [71]. Recently, Kwon et al. synthesized degradable PEI by partial conjugation of LMW PEI (800 Da) using acid-degradable amine-bearing ketal. PEI ketalization facilitated dissociation of the polymeric complexes upon hydrolysis and released DNA, thus improved transfection activity which also showed less toxicity [71]. They also tried to optimize the ketalization of LMW PEI ( $800 \mathrm{Da}$ ) to maximize the efficacy of the gene carrier. They found that ketalization ratios up to $70 \%$ showed the increase in transfection efficiency in NIH3T3 cells, although higher ketalization of $90 \%$ dramatically decreased the transfection activity of the carrier [72].

\section{Specific Ligand Modification of Degradable PEIs}

DNA or siRNA has to be delivered through extracellular and intracellular barriers to reach to the cellular nucleus or cytosol. One of the most used strategies to overcome the extracellular barrier in the polymeric gene delivery system is to introduce specific ligand to the gene carrier for specific binding of the ligand to the cell receptors and enhancing the transfection efficiency of the DNA or gene silencing using siRNA. In this section, we will discuss several specific ligands attached to the degradable PEIs.

4.1. Galactose. Galactose has been reported for targeting parenchymal cells in the liver cells because hepatocytes of the parenchymal cells have large numbers of cell surface receptors that recognize and bind molecules with exposed galactose residues in the carrier [73]. To introduce the hepatocyte target-specificity, Jiang et al. attached the galactosemoiety into the chitosan-graft-PEI as shown in Figure 13 to prepare galactose-containing chitosan-graft-PEI (GCGP) [74] to achieve hepatocyte-specificity. Their results showed that the GCGP transfected HepG2 cells containing much more asialoglycoprotein receptors (ASGPRs) than HeLa cells without the receptors, suggesting the receptor-mediated cellular internalization of GCGP. This degradable grafted 
PEI displayed higher transfection efficiency in mice liver after intraperitoneal administration of the carrier [74]. The problems associated with GCGP were their tendency to aggregate and insufficient capability to avoid the serum protein adsorbance in the blood stream. To overcome these drawbacks, they introduced PEG into the GCGP to synthesize the galactosylated-PEG-chitosan-graft-PEI (GPCGP) gene carrier as shown in Figure 14 [75]. Here, PEG helped to increase solubility of the polymer, decrease aggregation of polyplexes as well as cellular toxicity and lower the opsonization with serum proteins in the systemic circulation [76]. The result thus demonstrated that ${ }^{99 \mathrm{~m}} \mathrm{TC}-\mathrm{PEI} / \mathrm{DNA}$ particles quickly gathered in the lungs, on the other hand, ${ }^{99 \mathrm{~m}}$ TC-GPCGP/DNA complexes accumulated in the lungs, liver, and heart due to the increased circulation time after intravenous injection into mice owing to hydrophilic nature of PEG. Further, ${ }^{99 \mathrm{~m}}$ TC-GPCGP/DNA complexes accumulated in the mice liver much more over the time compared to that of ${ }^{99 \mathrm{~m}} \mathrm{TC}-\mathrm{PEI} / \mathrm{DNA}$ and ${ }^{99 \mathrm{~m}} \mathrm{TC}$-chitosangraft-PEI/DNA complexes, because of the specific interaction between the galactose-moieties and ASGPRs in hepatocytes [75].

4.2. Mannose. The mannose receptors are present on the surfaces of macrophages and dendritic cells as the antigenpresenting cells (APCs). The APCs expressing high levels of mannose receptors are used to mediate endocytosis and phagocytosis of a variety of antigens that expose mannose [77]. Jiang et al. prepared mannosylated chitosan-g-PEI through thiourea reaction between isothiocyanate groups of mannopyranosyl phenylisothiocyanate and amine ones of chitosan-g-PEI for macrophage targeting as shown in Figure 15 [78]. The polymer exhibited higher transfection efficiency than chitosan-g-PEI with lower cytotoxicity in RAW264.7 cells having mannose receptors due to the specific interaction of mannose receptors or RAW264.7 cells and mannose in the carrier, indicating of receptor-mediated endocytosis.

4.3. Folic Acid. Folic acid (FA) is a ligand targeting cancer cells because folate receptors (FRs) are overexpressed on many human cancer cell surfaces and FA has high affinity to the FRs $(\mathrm{Kd}<1 \mathrm{nM})$ [79]. Jiang et al. prepared folate-chitosan-g-PEI (FC-g-PEI) through the imine reaction between periodate-oxidized folated chitosan and LMW PEI (1800 Da) for delivery of Akt1 shRNA to FRs-overexpressing cancer cells as shown in Figure 16(a) [80]. The FC-g-PEI showed higher gene expression in KB cells having FRs than chitosan-g-PEI with lower toxicity. Also aerosol delivery of FC-g-PEI/Akt1 shRNA complexes suppressed mouse lung tumorigenesis in a urethane-induced lung cancer model mouse through the Akt1 signaling pathway mechanism, suggesting that the FC-g-PEI might be useful for shRNAbased gene therapy. Arote et al. also introduced FA into poly (ester amine) (PAE) based on PCL and LMW PEI to deliver TAM gene as a therapeutic gene for the tumor targeting as shown in Figure 16(b) [81]. The folate-PEG-PEA was found to have a high affinity for FR-positive cells compared to PEA without FA and higher transfection efficiency in FR-positive cells than FR-negative ones. Also folate-PEG-PEA exhibited marked antitumor activity against FR-positive KB tumors in mice through subcutaneous injection of TAM69 gene into the tumors of $\mathrm{BALB} / \mathrm{c}$ mice. Furthermore, the therapeutic effect by the folate-PEG-PEA/TAM gene complexes occurred in the apparent absence of weight loss or noticeable tumor apoptosis.

4.4. Peptide and Protein. It is worth mentioning that the disulfide linkage-contained PEIs are highly effective to increase transfection activity, however, not encouraging for in vivo system due to their nonspecific interaction with the anionic components such as blood cells and plasma protein, which exhibit polyplexes instability with nonspecificity for gene targeting. To circumvent these bottlenecks, specific cellbinding ligands have been introduced to the carrier for particular target of interest with high specificity. Sun et al. modified the disulfide-containing degradable PEI with RGD peptide, a specific ligand for targeting the integrin receptors that were expressed on most of the cell surfaces, for receptor-mediated endocytosis of the carrier [31]. The problem, however, was the inefficient transfection capability of the RGD-conjugated polyplexes in HeLa cells, because the binding between polyplexes containing RGD and the cell surface integrins was inhibited by the interactions between the surplus RGD and the integrin receptors. They further modified the disulfide-carrying degradable PEI with biotinylated transferrin for p53 gene delivery since the tumor cells overexpress transferrin receptors [82]. A high transfection capability was shown by the synthesized polymers in HepG2 as well as HeLa cells due to the specific interactions between the transferrin ligands and their tumor cell receptors [83]. In another study, Hwang et al. reported rabies virus glycoprotein (RVG) peptide-conjugated disulfide containing degradable PEI for target-specific delivery of micro-RNA (miRNA) to the parenchyma of brain. The result demonstrated an enhanced accumulation of miRNA in the brain through a highly neuron-specific targeting of the polymer/miRNA complexes by the RVG peptide after injection into mice via tail veins [84].

Huang et al. conjugated oligopeptide with degradable grafted PEI based on 2-hydroxypropyl- $\gamma$-CD and LMW PEI (600 Da) for targeting human epidermal growth factor receptor 2 (HER2) overexpressed in many breast and ovarian cancer [85]. The polymer exhibited strong targeting specificity to HER2 receptor and high transfection efficiency in HER2-positive human ovarian cancer SKOV-3 cells. Also the carrier significantly increased the antitumor effect on tumor bearing nude mice as compared to PEI $(25 \mathrm{kDa})$ through delivery of therapeutic interferon- $\alpha$ gene. They also coupled another oligopeptide with degradable grafted PEI based on $\beta$-CD and LMW PEI $(600 \mathrm{Da})$ for targeting epidermal growth factor receptor (EGFR)-2 as the EGFR is overexpressed in epithelial derived cancer cells [86]. The carrier had the highly efficient gene expression in the EGFRpositive liver cancer cells and achieved favorable inhibition 
of tumor growth in vivo by delivery of acetylcholinesterase gene.

Recently, Liu et al. coupled bifunctional peptide of RADC-Tat having tumor targeting and cell penetrating properties introduced to degradable PEI obtained by crosslinking of LMW PEI (2000 Da) with Pluronic P123 through carbamate bond between P123 and PEI [87]. The polymer showed higher transfection efficiency in HeLa and B16 cells with a lower cytotoxicity in comparison with PEI $(25 \mathrm{kDa})$ due to the tumor targeting by the RGD peptide and enhanced cell penetration by the Tat peptide. Zeng et al. introduced biotinylated transferrin into avidin and biotinylated degradable PEI obtained by reaction of cystamine bisacrylamide and LMW PEI $(800 \mathrm{Da})$ through disulfide linkage for tumor targeting [83] because the tumor cells with a high proliferation usually overexpress transferrin receptors [88]. The polymer showed higher transfection efficiency in HeLa and HepG2 with much lower toxicity owing to the specific interaction between receptors on the tumor cells and transferrin ligands.

\section{Degradable PEIs as Carrier System for Delivery of Small Interfering RNA}

The discovery of Nobel Prize Winning RNA interference (RNAi) concept by Fire and Mello in 1998 has considerably explored our understanding on the effective and targeted gene silencing over the last decade [89]. Moreover, several successful investigations on siRNA [90-92] led the experts in this field to give more considerable efforts in the progress of siRNA therapeutics for the effective treatment against various incurable diseases, including viral infections and cancers [38, 93-95]. However, delivery of siRNA is still the prime hurdle for its potential therapeutic applications, since naked siRNA is ineffective in most of the cases due to their too large size $(\sim 13 \mathrm{kDa})$ and negative charges, thus unable to freely cross the cellular membrane. Hence, design of an effective and safe delivery system for siRNA is a priority demand to be established as an efficient alternative approach for RNAi-oriented study. The concept on designing the degradable PEI derivatives possesses enormous potentials as an alternative carrier system for siRNA, although this strategy is waiting to be saturated at the moment.

Tarcha et al. demonstrated the first report on degradable PEI based on beta-aminopropionamide-contained chemically condensed LMW PEI. The polymer was synthesized through Michael addition reaction between the LMW PEI $(800 \mathrm{Da})$ and hexanediol diacrylate to increase chemical stability relative to the ester containing polymers with better degradability through amide-linkages. The synthesized degradable PEI provided enhanced knockdown of luciferase gene of about $80 \%$ compared to that of nontargeting scrambled siRNA in stably transfected HUH7 cells [96].

Disulfide-cross-linked degradable LMW PEI also applied for efficient delivery of siRNA [97]. The study investigated the correlation between cellular internalization and RNAibased efficacy among linear, cross-linked, and branched PEI and indicated that the branching polymer exhibited more efficient siRNA uptake, whereas the release of siRNA was accelerated through cross-linked PEI, indicating the importance of the combination of a high branching and reductively cleavable linkages within degradable PEI to become a clinically successful candidate on improving siRNA-based delivery. In another report, Kwon and coworkers synthesized ketalized linear degradable PEI by reaction between linear PEI $(2.5 \mathrm{kDa})$ and acrylated ketal monomer for successful delivery of siRNA into the cells [98]. The ketalized degradable PEI/siRNA system showed much higher gene silencing capability compared to that of unmodified PEI through the selective cytoplasmic localization and effective disassembly of the complexes prompted successful siRNA release in the cytoplasm owing to the acidic hydrolysis of the ketal linkages [98].

Jere and coworkers extensively investigated various degradable PEI derivatives for siRNA delivery purpose. They synthesized degradable PEI based on LMW PEI (423 Da) and PEG diacrylate (258 Da) for delivery of si/sh (small hairpin) RNA in lung cancer cell model [99]. The degradable PEI system showed enhanced gene silencing capability using a model siRNA targeting green fluorescence protein (GFP) in A549 cells, which was 1.5-fold higher compared to the PEI $25 \mathrm{kDa}$ and also showed less toxic effects. Furthermore, the polymer efficiently silenced the oncoprotein Akt1 by the delivery of Akt1 shRNA, which also interfered cancercell growth through knockdown of Akt1 in a target-specific manner owing to mainly the nature of polymer degradation. Akt1, known as protein kinase B, is an essential regulator of cell survival [100] and plays a major role in cell proliferation, inhibition of apoptosis, and regulation of protein translation, thus cancer progression [101]. Considering this, they investigated the in vivo efficacy of the degradable PEI/Akt1 siRNA complexes after aerosol administration into the Kras and urethane-induced lung cancer model mice. The result showed significant suppression of Akt1 mRNA and protein levels through the aerosol-administered Akt1 siRNA without affecting Akt2 and Akt3. Moreover, the number of tumors and the average tumor diameter were reduced significantly through the Akt1 siRNA-mediated treatment using degradable PEI as the carrier system [102].

\section{Conclusion}

Polymeric gene carriers have been extensively studied over the couple of decades, where cationic PEI-mediated gene vectors have been widely investigated due to their ability to stably condense of DNA and its delivery to cells as well. However, toxicity of PEI has been the prime concern for PEIbased gene carriers because of their nondegradable nature, although PEI-mediated toxicity generally depends on MW and type of PEI structure. Many researchers suggested that the linear and LMW PEIs are more tolerable compared to the branched and high MW ones. Considering the facts, synthesis of degradable PEIs, especially, degradable LMW linear or branched PEIs, has been increasingly studied after cross-linking or grafting using various degradable agents. Here, we comprehensively reviewed the synthesis and 
generation of various degradable PEI derivatives possessing many desirable properties as potent and safe carrier system for DNA and siRNA in vitro and in vivo. Although various degradable cross-linkers as well as grafted compounds have been applied to synthesize degradable PEIs, the esters or disulfide cross-linkages have been found superior in vitro and in vivo in terms of improving cellular tolerability as well as transfection activity or silencing. Other cross-linked or grafted PEIs are also effective in lowering cytotoxicity and in increasing gene transfection, although more extensive investigations are required. Furthermore, the relationship of PEI structure towards regulation of its cellular toxicity and transfection efficiency should be more elaborately studied to find the optimized degradable PEI candidates as effective gene or siRNA carriers. Also appropriate selections of crosslinkers and/or grafted molecules are essentially important to synthesize degradable PEI derivatives with unique and novel properties. Such a degradable PEI has been recently reported by our group, where the synthesized polymer comprised a polysorbitol cross-linked backbone to its PEI chain, exhibited unique transporter mechanism for accelerated cellular internalization mainly due to polysorbitol cross-linkages. Therefore, appropriate use of cross-linkers or grafted molecules can not only introduce degradable properties to the modified PEI but also be useful to ornament with other functional properties such as accelerating cellular uptake as well as high intracellular selectivity. In this regards, more pharmacodynamic or pharmacokinetic aspects as well as comprehensive in vivo characterizations should be necessarily investigated since a vast of the studies were carried out in vitro or in mouse models to find mechanisms or therapeutic effects. It is expected that the more updated and optimized research on designing nonviral carriers, especially development of degradable PEIs, will expand the use of these systems to design and develop a safe and potent DNA or siRNA carrier for practical applications against various incurable diseases and disorders in near future for the betterment of humankind.

\section{References}

[1] D. Putnam, "Polymers for gene delivery across length scales," Nature Materials, vol. 5, no. 6, pp. 439-451, 2006.

[2] D. C. Górecki, "Prospects and problems of gene therapy: an update," Expert Opinion on Emerging Drugs, vol. 6, no. 2, pp. 187-198, 2001.

[3] C. Sheridan, "Gene therapy finds its niche," Nature Biotechnology, vol. 29, no. 2, pp. 121-128, 2011.

[4] C. E. Thomas, A. Ehrhardt, and M. A. Kay, "Progress and problems with the use of viral vectors for gene therapy," Nature Reviews Genetics, vol. 4, no. 5, pp. 346-358, 2003.

[5] M. A. Mintzer and E. E. Simanek, "Nonviral vectors for gene delivery," Chemical Reviews, vol. 109, no. 2, pp. 259-302, 2009.

[6] D. J. Glover, H. J. Lipps, and D. A. Jans, "Towards safe, nonviral therapeutic gene expression in humans," Nature Reviews Genetics, vol. 6, no. 4, pp. 299-310, 2005.

[7] D. W. Pack, A. S. Hoffman, S. Pun, and P. S. Stayton, "Design and development of polymers for gene delivery," Nature Reviews Drug Discovery, vol. 4, no. 7, pp. 581-593, 2005.
[8] S. Y. Wong, J. M. Pelet, and D. Putnam, "Polymer systems for gene delivery-Past, present, and future," Progress in Polymer Science, vol. 32, no. 8-9, pp. 799-837, 2007.

[9] D. Jere, H. L. Jiang, R. Arote et al., "Degradable polyethylenimines as DNA and small interfering RNA carriers," Expert Opinion on Drug Delivery, vol. 6, no. 8, pp. 827-834, 2009.

[10] X. Gao, K. S. Kim, and D. Liu, "Nonviral gene delivery: what we know and what is next," The AAPS Journal, vol. 9, pp. E92E104, 2007.

[11] D. A. Jackson, S. Juranek, and H. J. Lipps, "Designing nonviral vectors for efficient gene transfer and long-term gene expression," Molecular Therapy, vol. 14, no. 5, pp. 613626, 2006.

[12] C. Louise, "Nonviral vectors," Methods in Molecular Biology, vol. 333, pp. 201-226, 2006.

[13] T. Merdan, J. Kopeček, and T. Kissel, "Prospects for cationic polymers in gene and oligonucleotide therapy against cancer," Advanced Drug Delivery Reviews, vol. 54, no. 5, pp. 715758, 2002.

[14] A. L. Parker, C. Newman, S. Briggs, L. Seymour, and P. J. Sheridan, "Nonviral gene delivery: techniques and implications for molecular medicine," Expert Reviews in Molecular Medicine, vol. 5, no. 22, pp. 1-15, 2003.

[15] O. Boussif, F. LezoualC'H, M. A. Zanta et al., “A versatile vector for gene and oligonucleotide transfer into cells in culture and in vivo: polyethylenimine," Proceedings of the National Academy of Sciences of the United States of America, vol. 92, no. 16, pp. 7297-7301, 1995.

[16] M. Breunig, U. Lungwitz, R. Liebl et al., "Gene delivery with low molecular weight linear polyethylenimines," Journal of Gene Medicine, vol. 7, no. 10, pp. 1287-1298, 2005.

[17] R. B. Arote, D. Jere, and C. S. Cho, "Biodegradable polyester derivatives as gene carriers. Current Trends in Polymer Science," Current Trends in Polymer Science, vol. 12, pp. 1-17, 2008.

[18] H. L. Jiang, R. Arote, D. Jere, Y. K. Kim, M. H. Cho, and C. S. Cho, "Degradable polyethylenimines as gene carriers," Materials Science and Technology, vol. 24, no. 9, pp. 11181126, 2008.

[19] M. A. Gosselin, W. Guo, and R. J. Lee, "Efficient gene transfer using reversibly cross-linked low molecular weight polyethylenimine," Bioconjugate Chemistry, vol. 12, no. 6, pp. 989-994, 2001.

[20] H. Petersen, T. Merdan, K. Kunath, D. Fischer, and T. Kissel, "Poly(ethylenimine-co-L-lactamide-co-succinamide): a biodegradable polyethylenimine derivative with an advantageous $\mathrm{pH}$-dependent hydrolytic degradation for gene delivery," Bioconjugate Chemistry, vol. 13, no. 4, pp. 812-821, 2002.

[21] M. L. Forrest, J. T. Koerber, and D. W. Pack, "A degradable polyethylenimine derivative with low toxicity for highly efficient gene delivery," Bioconjugate Chemistry, vol. 14, no. 5, pp. 934-940, 2003.

[22] J. Kloeckner, E. Wagner, and M. Ogris, "Degradable gene carriers based on oligomerized polyamines," European Journal of Pharmaceutical Sciences, vol. 29, no. 5, pp. 414-425, 2006.

[23] J. Kloeckner, S. Bruzzano, M. Ogris, and E. Wagner, "Gene carriers based on hexanediol diacrylate linked oligoethylenimine: effect of chemical structure of polymer on biological properties," Bioconjugate Chemistry, vol. 17, no. 5, pp. 13391345, 2006.

[24] M. R. Park, K. O. Han, I. K. Han et al., "Degradable polyethylenimine-alt-poly(ethylene glycol) copolymers as 
novel gene carriers," Journal of Controlled Release, vol. 105, no. 3, pp. 367-380, 2005.

[25] D. G. Anderson, A. Akinc, N. Hossain, and R. Langer, "Structure/property studies of polymeric gene delivery using a library of poly ( $\beta$-amino esters)," Molecular Therapy, vol. 11, no. 3, pp. 426-434, 2005.

[26] D. C. Wu, Y. Liu, X. Jiang, C. B. He, S. H. Goh, and K. W. Leong, "Hyperbranched poly(amino ester)s with different terminal amine groups for DNA delivery," Biomacromolecules, vol. 7, no. 6, pp. 1879-1883, 2006.

[27] C. H. Ahn, S. Y. Chae, Y. H. Bae, and S. W. Kim, "Biodegradable poly(ethylenimine) for plasmid DNA delivery," Journal of Controlled Release, vol. 80, no. 1-3, pp. 273-282, 2002.

[28] Y. H. Kim, J. H. Park, M. Lee, Y. H. Kim, T. G. Park, and S. W. Kim, "Polyethylenimine with acid-labile linkages as a biodegradable gene carrier," Journal of Controlled Release, vol. 103, no. 1, pp. 209-219, 2005.

[29] C. Lin and J. F. J. Engbersen, "Effect of chemical functionalities in poly(amido amine)s for non-viral gene transfection," Journal of Controlled Release, vol. 132, no. 3, pp. 267-272, 2008.

[30] H. W. Zhang and S. V. Vinogradov, "Short biodegradable polyamines for gene delivery and transfection of brain capillary endothelial cells," Journal of Controlled Release, vol. 143, no. 3, pp. 359-366, 2010.

[31] Y. X. Sun, X. Zeng, Q. F. Meng, X. Z. Zhang, S. X. Cheng, and R. X. Zhuo, "The influence of RGD addition on the gene transfer characteristics of disulfide-containing polyethyleneimine/DNA complexes," Biomaterials, vol. 29, no. 32, pp. 4356-4365, 2008.

[32] Q. Peng, Z. Zhong, and R. Zhuo, "Disulfide cross-linked polyethylenimines (PEI) prepared via thiolation of low molecular weight PEI as highly efficient gene vectors," Bioconjugate Chemistry, vol. 19, no. 2, pp. 499-506, 2008.

[33] M. Breunig, U. Lungwitz, R. Liebl, and A. Goepferich, "Breaking up the correlation between efficacy and toxicity for nonviral gene delivery," Proceedings of the National Academy of Sciences of the United States of America, vol. 104, no. 36, pp. 14454-14459, 2007.

[34] T. H. Kim, S. E. Cook, R. B. Arote et al., "A degradable hyperbranched poly(ester amine) based on poloxamer diacrylate and polyethylenimine as a gene carrier," Macromolecular Bioscience, vol. 7, no. 5, pp. 611-619, 2007.

[35] R. P. Arote, T. H. Kim, Y. K. Kim et al., "A biodegradable poly(ester amine) based on polycaprolactone and polyethylenimine as a gene carrier," Biomaterials, vol. 28, no. 4, pp. 735-744, 2007.

[36] R. B. Arote, S. K. Hwang, M. K. Yoo et al., "Biodegradable poly(ester amine) based on glycerol dimethacrylate and polyethylenimine as a gene carrier," Journal of Gene Medicine, vol. 10, no. 11, pp. 1223-1235, 2008.

[37] M. A. Islam, C. H. Yun, Y. J. Choi et al., "Accelerated gene transfer through a polysorbitol-based transporter mechanism," Biomaterials, vol. 32, pp. 9908-9924, 2011.

[38] G. W. Moeckel, L. Zhang, A. B. Fogo, C. M. Hao, A. Pozzi, and M. D. Breyer, "COX 2 activity promotes organic osmolyte accumulation and adaptation of renal medullary interstitial cells to hypertonic stress," Journal of Biological Chemistry, vol. 278, no. 21, pp. 19352-19357, 2003.

[39] T. X. Yang, Y. N. Huang, L. E. Heasley, T. Berl, J. B. Schnermann, and J. P. Briggs, "MAPK mediation of hypertonicitystimulated cyclooxygenase- 2 expression in renal medullary collecting duct cells," Journal of Biological Chemistry, vol. 275, no. 30, pp. 23281-23286, 2000.

[40] S. H. Pun, N. C. Bellocq, A. Liu et al., "Cyclodextrin-modified polyethylenimine polymers for gene delivery," Bioconjugate Chemistry, vol. 15, no. 4, pp. 831-840, 2004.

[41] G. P. Tang, H. Y. Guo, F. Alexis et al., "Low molecular weight polyethylenimines linked by $\beta$-cyclodextrin for gene transfer into the nervous system," Journal of Gene Medicine, vol. 8, no. 6, pp. 736-744, 2006.

[42] C. A. Yang, H. Z. Li, S. H. Goh, and J. Li, "Cationic star polymers consisting of $\alpha$-cyclodextrin core and oligoethylenimine arms as nonviral gene delivery vectors," Biomaterials, vol. 28, no. 21, pp. 3245-3254, 2007.

[43] T. H. Kim, S. I. Kim, T. Akaike, and C. S. Cho, "Synergistic effect of poly(ethylenimine) on the transfection efficiency of galactosylated chitosan/DNA complexes," Journal of Controlled Release, vol. 105, no. 3, pp. 354-366, 2005.

[44] K. Wong, G. B. Sun, X. Q. Zhang et al., "PEI-g-chitosan, a novel gene delivery system with transfection efficiency comparable to polyethylenimine in vitro and after liver administration in vivo," Bioconjugate Chemistry, vol. 17, no. 1, pp. 152-158, 2006.

[45] H. L. Jiang, Y. K. Kim, R. Arote et al., "Chitosan-graftpolyethylenimine as a gene carrier," Journal of Controlled Release, vol. 117, no. 2, pp. 273-280, 2007.

[46] Y. L. Lou, Y. S. Peng, B. H. Chen, L. F. Wang, and K. W. Leong, "Poly(ethylene imine)-g-chitosan using EX-810 as a spacer for nonviral gene delivery vectors," Journal of Biomedical Materials Research A, vol. 88, no. 4, pp. 1058-1068, 2009.

[47] B. Lu, X. D. Xu, X. Z. Zhang, S. X. Cheng, and R. X. Zhuo, "Low molecular weight polyethylenimine grafted Nmaleated chitosan for gene delivery: properties and in vitro transfection studies," Biomacromolecules, vol. 9, no. 10, pp. 2594-2600, 2008.

[48] Y. X. Sun, W. Xiao, S. X. Cheng, X. Z. Zhang, and R. X. Zhuo, "Synthesis of (Dex-HMDI)-g-PEIs as effective and low cytotoxic nonviral gene vectors," Journal of Controlled Release, vol. 128, no. 2, pp. 171-178, 2008.

[49] Y. X. Sun, X. Z. Zhang, H. Cheng, S. X. Cheng, and R. X. Zhuo, "A low-toxic and efficient gene vector: carboxymethyl dextran-graft- polyethylenimine," Journal of Biomedical Materials Research A, vol. 84, no. 4, pp. 11021110, 2008.

[50] Z. F. Zhang, C. H. Yang, Y. Duan et al., "Poly(ethylene glycol) analogs grafted with low molecular weight poly (ethylene imine) as non-viral gene vectors," Acta Biomaterialia, vol. 6, no. 7, pp. 2650-2657, 2010.

[51] J. H. Yu, J. S. Quan, J. Huang et al., “ $\alpha, \beta$-Poly(l-aspartategraft-PEI): a pseudo-branched PEI as a gene carrier with low toxicity and high transfection efficiency," Acta Biomaterialia, vol. 5, no. 7, pp. 2485-2494, 2009.

[52] J. H. Yu, J. S. Quan, J. T. Kwon et al., "Fabrication of a novel core-shell gene delivery system based on a brush-like polycation of $\alpha, \beta$-poly (L-aspartate-graft-PEI)," Pharmaceutical Research, vol. 26, no. 9, pp. 2152-2163, 2009.

[53] M. R. Park, H. W. Kim, C. S. Hwang et al., "Highly efficient gene transfer with degradable poly(ester amine) based on poly(ethylene glycol) diacrylate and polyethylenimine in vitro and in vivo," The Journal of Gene Medicine, vol. 10, no. 2, pp. 198-207, 2008.

[54] J. H. Yu, J. S. Quan, J. Huang, J. W. Nah, and C. S. Cho, "Degradable poly(amino ester) based on poly(ethylene 
glycol) dimethacrylate and polyethylenimine as a gene carrier: molecular weight of PEI affects transfection efficiency," Journal of Materials Science, vol. 20, no. 12, pp. 2501-2510, 2009.

[55] Q. P. Luu, J. Y. Shin, Y. K. Kim et al., "High gene transfer by the osmotic polysorbitol-mediated transporter through the selective caveolae endocytic pathway," Molecular Pharmaceutics, vol. 9, pp. 2206-2218, 2012.

[56] T. E. Park, B. Kang, Y. K. Kim et al., "Selective stimulation of caveolae-mediated endocytosis by an osmotic polymannitolbased gene transporter," Biomaterials, vol. 33, pp. 7272-7281, 2012.

[57] C. Lin and J. F. J. Engbersen, "The role of the disulfide group in disulfide-based polymeric gene carriers," Expert Opinion on Drug Delivery, vol. 6, no. 4, pp. 421-439, 2009.

[58] G. Wu, Y. Z. Fang, S. Yang, J. R. Lupton, and N. D. Turner, "Glutathione metabolism and its implications for health," The Journal of Nutrition, vol. 134, no. 3, pp. 489-492, 2004.

[59] S. Bauhuber, R. Liebl, L. Tomasetti, R. Rachel, A. Goepferich, and M. Breunig, "A library of strictly linear poly(ethylene glycol)-poly(ethylene imine) diblock copolymers to perform structure-function relationship of non-viral gene carriers," Journal of Controlled Release, vol. 162, pp. 446-455, 2012.

[60] G. Zhang, J. Liu, Q. Yang, R. Zhuo, and X. Jiang, "Disulfidecontaining brushed polyethylenimine derivative synthesized by click chemistry for nonviral gene delivery," Bioconjug Chemistry, vol. 23, pp. 1290-1299, 2012.

[61] Y. Ping, C. Liu, Z. Zhang, K. L. Liu, J. Chen, and J. Li, "Chitosan-graft-(PEI-beta-cyclodextrin) copolymers and their supramolecular PEGylation for DNA and siRNA delivery," Biomaterials, vol. 32, pp. 8328-8341, 2011.

[62] D. H. Jiang and A. K. Salem, "Optimized dextranpolyethylenimine conjugates are efficient non-viral vectors with reduced cytotoxicity when used in serum containing environments," International Journal of Pharmaceutics, vol. 427, pp. 71-79, 2012.

[63] S. L. Xu, M. Chen, Y. Yao et al., "Novel poly(ethylene imine) biscarbamate conjugate as an efficient and nontoxic gene delivery system," Journal of Controlled Release, vol. 130, no. 1, pp. 64-68, 2008.

[64] X. Y. Liu, W. Y. Ho, W. J. Hung, and M. D. Shau, "The characteristics and transfection efficiency of cationic poly (ester-co-urethane)—short chain PEI conjugates selfassembled with DNA," Biomaterials, vol. 30, no. 34, pp. 66656673, 2009.

[65] D. Zhao, T. Gong, D. Zhu, Z. Zhang, and X. Sun, "Comprehensive comparison of two new biodegradable gene carriers," International Journal of Pharmaceutics, vol. 413, no. 1-2, pp. 260-270, 2011.

[66] Y. Wang, J. Su, F. Wu et al., "Biscarbamate cross-linked polyethylenimine derivative with low molecular weight, low cytotoxicity, and high efficiency for gene delivery," International Journal of Nanomedicine, vol. 7, pp. 693-704, 2012.

[67] M. P. Xiong, M. Laird Forrest, G. Ton, A. Zhao, N. M. Davies, and G. S. Kwon, "Poly(aspartate-g-PEI800), a polyethylenimine analogue of low toxicity and high transfection efficiency for gene delivery," Biomaterials, vol. 28, no. 32, pp. 4889-4900, 2007.

[68] B. Lu, Y. X. Sun, Y. Q. Li, X. Z. Zhang, and R. X. Zhuo, "N-Succinyl-chitosan grafted with low molecular weight polyethylenimine as a serum-resistant gene vector," Molecular BioSystems, vol. 5, no. 6, pp. 629-637, 2009.
[69] Y. T. Wen, S. R. Pan, X. Luo, X. Zhang, W. Zhang, and M. Feng, "A biodegradable low molecular weight polyethylenimine derivative as low toxicity and efficient gene vector," Bioconjugate Chemistry, vol. 20, no. 2, pp. 322-332, 2009.

[70] R. Namgung, J. Kim, K. Singha, C. H. Kim, and W. J. Kim, "Synergistic effect of low cytotoxic linear polyethylenimine and multiarm polyethylene glycol: study of physicochemical properties and in vitro gene transfection," Molecular Pharmaceutics, vol. 6, no. 6, pp. 1826-1835, 2009.

[71] M. S. Shim and Y. J. Kwon, "Controlled delivery of plasmid DNA and siRNA to intracellular targets using ketalized polyethylenimine," Biomacromolecules, vol. 9, no. 2, pp. 444455, 2008.

[72] M. S. Shim and Y. J. Kwon, "Controlled cytoplasmic and nuclear localization of plasmid DNA and siRNA by differentially tailored polyethylenimine," Journal of Controlled Release, vol. 133, no. 3, pp. 206-213, 2009.

[73] E. Newfeld and G. Ashwell, "Carbohydrate recognizable systems for receptor-mediated pinocytosis," in Biochemistry of Glycoprotein and Proteoglycans, W. Lennartz, Ed., pp. 241266, Plenum Press, New York, NY, USA, 1979.

[74] H. L. Jiang, J. T. Kwon, Y. K. Kim et al., "Galactosylated chitosan-graft-polyethylenimine as a gene carrier for hepatocyte targeting," Gene Therapy, vol. 14, no. 19, pp. 1389-1398, 2007.

[75] H. L. Jiang, J. T. Kwon, E. M. Kim et al., "Galactosylated poly(ethylene glycol)-chitosan-graft-polyethylenimine as a gene carrier for hepatocyte-targeting," Journal of Controlled Release, vol. 131, no. 2, pp. 150-157, 2008.

[76] S. J. Sung, S. H. Min, K. Y. Cho et al., "Effect of polyethylene glycol on gene delivery of polyethylenimine," Biological and Pharmaceutical Bulletin, vol. 26, no. 4, pp. 492-500, 2003.

[77] W. P. Jian, W. J. Swiggard, C. Heufler et al., "The receptor DEC-205 expressed by dendritic cells and thymic epithelial cells is involved in antigen processing," Nature, vol. 375, no. 6527, pp. 151-155, 1995.

[78] H. L. Jiang, Y. K. Kim, R. Arote et al., "Mannosylated chitosan-graft-polyethylenimine as a gene carrier for Raw 264.7 cell targeting," International Journal of Pharmaceutics, vol. 375, no. 1-2, pp. 133-139, 2009.

[79] A. C. Antony, "Folate receptors," Annual Review of Nutrition, vol. 16, pp. 501-521, 1996.

[80] H. L. Jiang, C. X. Xu, Y. K. Kim et al., "The suppression of lung tumorigenesis by aerosol-delivered folate-chitosangraft-polyethylenimine/Akt1 shRNA complexes through the Akt signaling pathway," Biomaterials, vol. 30, no. 29, pp. 5844-5852, 2009.

[81] R. B. Arote, S. K. Hwang, H. T. Lim et al., "The therapeutic efficiency of FP-PEA/TAM67 gene complexes via folate receptor-mediated endocytosis in a xenograft mice model," Biomaterials, vol. 31, no. 8, pp. 2435-2445, 2010.

[82] Z. M. Qian, H. Li, H. Sun, and K. Ho, "Targeted drug delivery via the transferrin receptor-mediated endocytosis pathway," Pharmacological Reviews, vol. 54, no. 4, pp. 561-587, 2002.

[83] X. Zeng, Y. X. Sun, W. Qu, X. Z. Zhang, and R. X. Zhuo, "Biotinylated transferrin/avidin/biotinylated disulfide containing PEI bioconjugates mediated p53 gene delivery system for tumor targeted transfection," Biomaterials, vol. 31, no. 17, pp. 4771-4780, 2010.

[84] D. W. Hwang, S. Son, J. Jang et al., "A brain-targeted rabies virus glycoprotein-disulfide linked PEI nanocarrier for delivery of neurogenic microRNA," Biomaterials, vol. 32, no. 21, pp. 4968-4975, 2011. 
[85] H. L. Huang, H. Yu, G. P. Tang, Q. Q. Wang, and J. Li, "Low molecular weight polyethylenimine cross-linked by 2hydroxypropyl- $\gamma$-cyclodextrin coupled to peptide targeting HER2 as a gene delivery vector," Biomaterials, vol. 31, no. 7, pp. 1830-1838, 2010.

[86] M. Liu, Z. H. Li, F. J. Xu et al., "An oligopeptide ligandmediated therapeutic gene nanocomplex for liver cancertargeted therapy," Biomaterials, vol. 33, pp. 2240-2250, 2012.

[87] K. H. Liu, X. Y. Wang, W. Fan et al., "Degradable polyethylenimine derivate coupled to a bifunctional peptide R13 as a new gene-delivery vector," International Journal of Nanomedicine, vol. 7, pp. 1149-1162, 2012.

[88] A. Dautry-Varsat, "Receptor-mediated endocytosis: the intracellular journey of transferrin and its receptor," Biochimie, vol. 68, no. 3, pp. 375-381, 1986.

[89] A. Fire, S. Xu, M. K. Montgomery, S. A. Kostas, S. E. Driver, and C. C. Mello, "Potent and specific genetic interference by double-stranded RNA in caenorhabditis elegans," Nature, vol. 391, no. 6669, pp. 806-811, 1998.

[90] S. M. Elbashir, J. Harborth, W. Lendeckel, A. Yalcin, K. Weber, and T. Tuschl, "Duplexes of 21-nucleotide RNAs mediate RNA interference in cultured mammalian cells," Nature, vol. 411, no. 6836, pp. 494-498, 2001.

[91] S. M. Elbashir, W. Lendeckel, and T. Tuschl, "RNA interference is mediated by 21-and 22-nucleotide RNAs," Genes and Development, vol. 15, no. 2, pp. 188-200, 2001.

[92] A. P. McCaffrey, L. Meuse, T. T. T. Pham, D. S. Conklin, G. J. Hannon, and M. A. Kay, "RNA interference in adult mice," Nature, vol. 418, no. 6893, pp. 38-39, 2002.

[93] F. Leuschner, P. Dutta, R. Gorbatov et al., "Therapeutic siRNA silencing in inflammatory monocytes in mice," Nature Biotechnology, vol. 29, pp. 1005-1010, 2011.

[94] K. T. Love, K. P. Mahon, C. G. Levins et al., "Lipid-like materials for low-dose, in vivo gene silencing," Proceedings of the National Academy of Sciences of the United States of America, vol. 107, no. 5, pp. 1864-1869, 2010.

[95] K. A. Whitehead, R. Langer, and D. G. Anderson, "Knocking down barriers: advances in siRNA delivery," Nature Review Drug Discovery, vol. 8, pp. 129-138, 2009.

[96] P. J. Tarcha, J. Pelisek, T. Merdan et al., "Synthesis and characterization of chemically condensed oligoethylenimine containing beta-aminopropionamide linkages for siRNA delivery," Biomaterials, vol. 28, no. 25, pp. 3731-3740, 2007.

[97] M. Breunig, C. Hozsa, U. Lungwitz et al., "Mechanistic investigation of poly(ethylene imine)-based siRNA delivery: disulfide bonds boost intracellular release of the cargo," Journal of Controlled Release, vol. 130, no. 1, pp. 57-63, 2008.

[98] M. S. Shim and Y. J. Kwon, "Acid-responsive linear polyethylenimine for efficient, specific, and biocompatible siRNA delivery," Bioconjugate Chemistry, vol. 20, no. 3, pp. 488-499, 2009.

[99] D. Jere, C. X. Xu, R. Arote, C. H. Yun, M. H. Cho, and C. S. Cho, "Poly ( $\beta$-amino ester $)$ as a carrier for si/shRNA delivery in lung cancer cells," Biomaterials, vol. 29, no. 16, pp. 25352547, 2008.

[100] I. Vivanco and C. L. Sawyers, "The phosphatidylinositol 3-kinase-AKT pathway in human cancer," Nature Reviews Cancer, vol. 2, no. 7, pp. 489-501, 2002.

[101] M. A. Lawlor and D. R. Alessi, "PKB/Akt: a key mediator of cell proliferation, survival and insulin responses?" Journal of Cell Science, vol. 114, no. 16, pp. 2903-2910, 2001.
[102] C. X. Xu, D. Jere, H. Jin et al., "Poly(ester amine)-mediated, aerosol-delivered Akt1 small interfering RNA suppresses lung tumorigenesis," American Journal of Respiratory and Critical Care Medicine, vol. 178, no. 1, pp. 60-73, 2008.

[103] Y. K. Kim, Q. P. Luu, M. A. Islam et al., "Degradable polyethylenimine derivatives as gene carriers," Nano Life, vol. 2, Article ID 1230004, 2012.

[104] M. A. Gosselin, W. Guo, and R. J. Lee, "Incorporation of reversibly cross-linked polyplexes into LPDII vectors for gene delivery," Bioconjugate Chemistry, vol. 13, no. 5, pp. 10441053, 2002.

[105] L. V. Christensen, C. W. Chang, J. K. Won et al., "Reducible poly(amido ethylenimine)s designed for triggered intracellular gene delivery," Bioconjugate Chemistry, vol. 17, no. 5, pp. 1233-1240, 2006.

[106] Y. Lee, H. Mo, H. Koo et al., "Visualization of the degradation of a disulfide polymer, linear poly(ethylenimine sulfide), for gene delivery," Bioconjugate Chemistry, vol. 18, no. 1, pp. 13$18,2007$.

[107] J. Liu, X. L. Jiang, L. Xu, X. M. Wang, W. E. Hennink, and R. X. Zhuo, "Novel reduction-responsive cross-linked polyethylenimine derivatives by click chemistry for nonviral gene delivery," Bioconjugate Chemistry, vol. 21, no. 10, pp. 1827-1835, 2010 . 

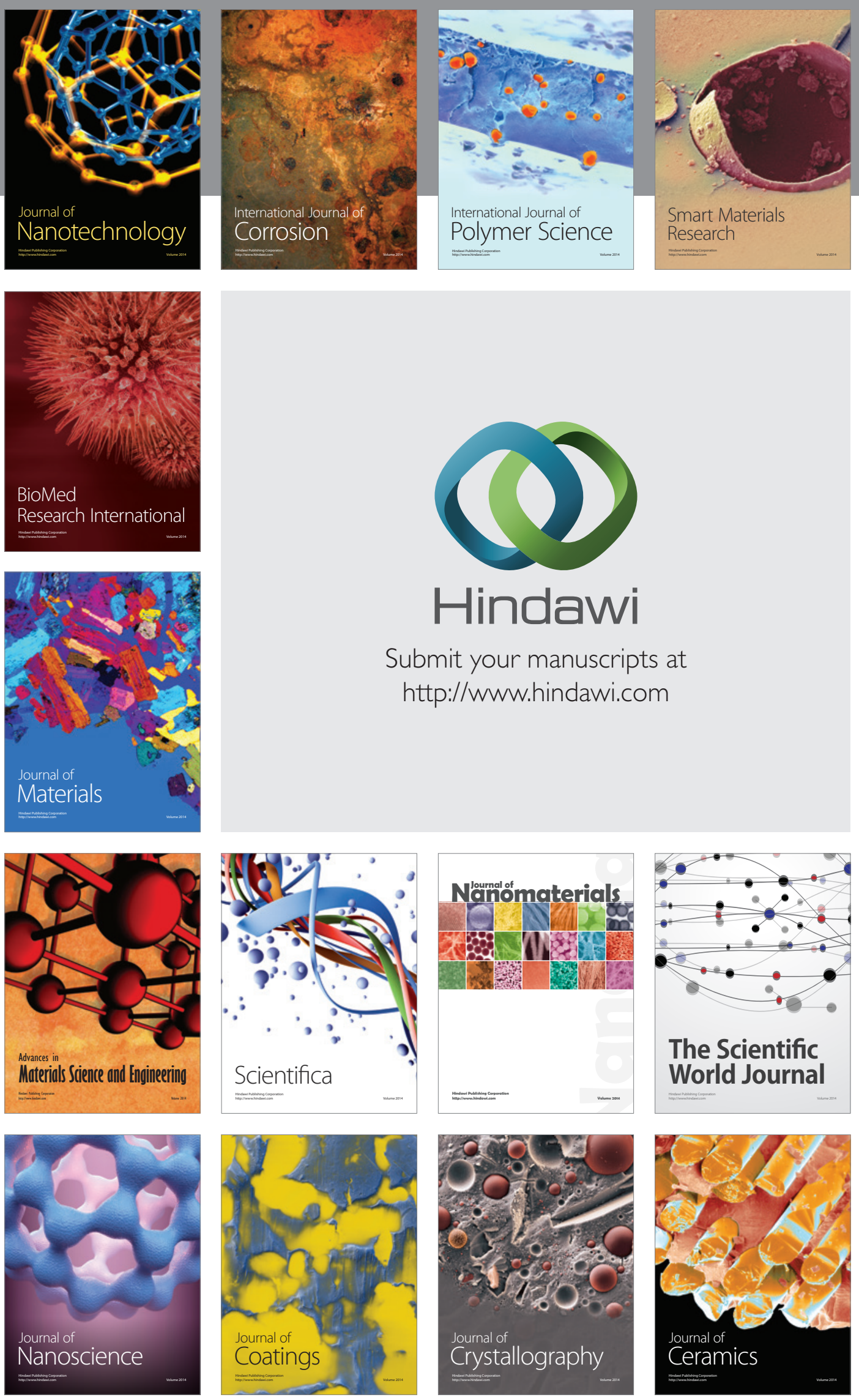

The Scientific World Journal

Submit your manuscripts at

http://www.hindawi.com

\section{World Journal}

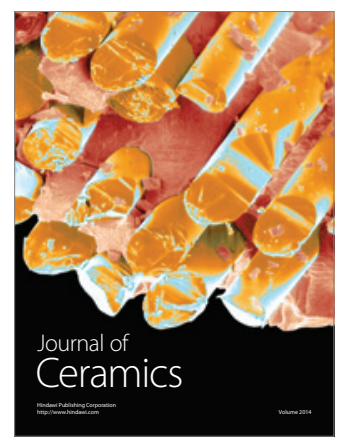

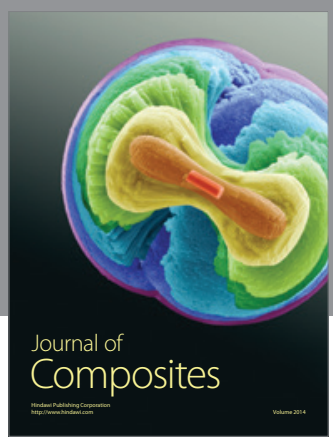
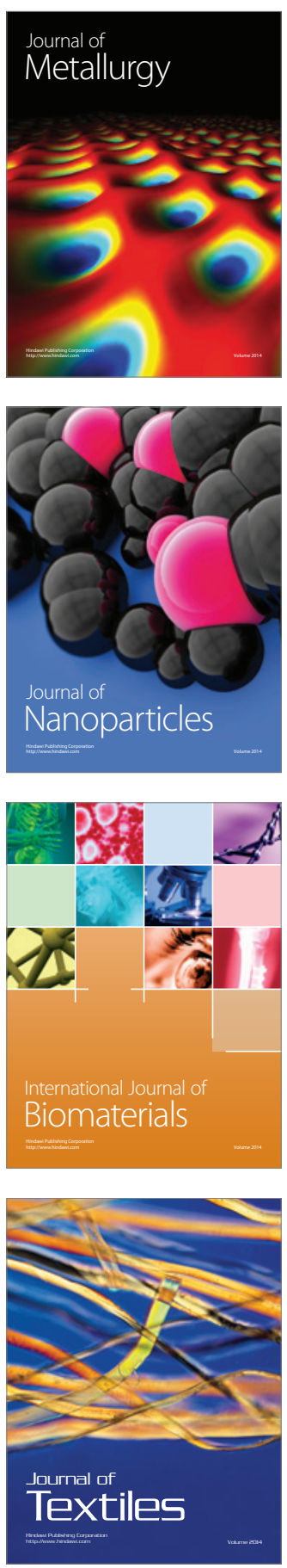